\title{
LES GLOSES BOTANIQUES ANDALOUSES SUR LE MANUSCRIT DE PARIS DE LA TRADUCTION ARABE DE LA MATERIA MEDICA DE DIOSCORIDES
}

\author{
ANDALUSIAN BOTANICAL GLOSSES IN THE PARIS \\ MANUSCRIPT ON ARABIC TRANSLATION OF MATERIA \\ MEDICA BY DIOSCORIDES
}

\author{
IBRAHIM Ben Mrad \\ Université de la Manouba, Tunis
}

\begin{abstract}
Se aborda en este trabajo el estudio de un precioso manuscrito de la Biblioteca Nacional de París, el n. ${ }^{\circ} 2849$ de los fondos árabes. Se trata de un manuscrito de origen andalusí que contiene la traducción al árabe de la $M a-$ teria Medica de Dioscórides, escrito en Siria a principios del siglo XIII, cuyos márgenes están repletos de glosas de naturaleza sinonímica, relativas a los nombres griegos que reciben las plantas descritas por la farmacología griega. Estas glosas son de orígen andalusí, y ofrecen una gran riqueza terminológica que se inscribe en un amplio movimiento árabe, y más concretamente andalusí, de revisión y comentario de la traducción árabe de la $M a-$ teria Medica. En la primera parte de este estudio se ofrece una presentación general del manuscrito, mostrando su valor para una reedición crítica de la obra, de las glosas que contiene y particularmente de las glosas botánicas andalusíes, insistiendo en su valor sinonímico y su contribución terminológica. En la segunda parte, el autor propone una edición crítica anotada de 44 glosas extraídas de la primera maqāla de la obra.
\end{abstract}

Palabras clave: glosas botánicas; glosadores andalusíes; traducción árabe; sinonimia; terminología; niveles de lenguaje; árabe andalusí ; latín español.
The following study focusses on a precious manuscript from the National Library in Paris, namely n. ${ }^{\circ} 2849$ of the Arabic manuscript collection. This is a manuscript of Andalusian origin of the Arabic translation of Materia Medica by Dioscorides, written in Syria at the beginning of the 13th century. Its margins are filled with glosses of synonymic nature, relating to the Greek terms of the plants described by the Greek pharmacologist and physician. These glosses, of Andalusian origin, offer a great terminological richness which is part of a large Arabic - mainly Andalusian - movement of revision and commentary of Materia Medica in Arabic. In the first part a general introduction to the manuscript is provided showing its significant value for a critical edition of the book, the glosses contained and, especially, of the Andalusian botanical glosses, insisting on their synonymic value and their terminological contribution. In a second part, a critical annotated edition of 44 glosses from the first maqāla of the book is proposed.

Key words: Botanical glosses; Andalusian commentators; Arabic translation; Synonymy; Terminology; Levels of language; Andalusian Arabic; Spanish Latin. 


\section{Le manuscrit et ses origines andalouses}

Il existe, dans le Fonds Arabe des manuscrits de la BN de Paris un manuscrit précieux de la Materia Medica $(=M M)$ du médecin pharmacologue grec du $1^{\text {er }}$ siècle de J.C., Pedanios Dioscorides d'Anazarbe, dans sa première traduction arabe $(=M M A)$ faite à Baghdād par Iștifān $b$. Basīl et corrigée par son maître Hunayn b. Ishạā, sous le règne du calife 'abbāside Ja'far al-Mutawakkil $(232 / 847-247 / 861)^{1}$. Le manuscrit porte le n. ${ }^{\circ} 2849$. Il contient 143 folios, dont les dimensions sont de 33,5 × 25,5 cm et de 23 lignes par page. Mais le texte de Dioscorides devait se terminer au folio $131 \mathrm{v} .^{\circ}$, avec la fin de la $V^{\text {ème }}$ maqāla, puisque l'attribution des deux maqāla traitant des poisons et des venins à Dioscorides a été souvent contestée ${ }^{2}$.

\footnotetext{
${ }^{1}$ Cette traduction est faite sur le texte original grec ; mais il existe deux autres traductions arabes faites au $\mathrm{VI}^{\mathrm{e} m e} / \mathrm{XII}^{\mathrm{e}}{ }^{\mathrm{eme}}$ siècle par deux savants peu connus, sur une traduction syriaque faite par Ḥunayn b. Isḥāq pour Bakhtīshū' b. Jibrīl (m. 256/870). La première version du VI ${ }^{\text {ème }}$ siècle est faite par un certain Abū Sālim al-Malți pour un prince des Artuqides de Diyār Bakr nommé Fakhr al-Dīn. La mauvaise qualité de cette traduction était à l'origine de la deuxième version, faite sur la même traduction syriaque de Hunayn, par un certain Mihrān b. Manșūr b. Mihrān à la demande de Abū l-Muzaffar Najm al-Dīn Alpī b. Timurtāsh b. Artuq (547/1252-572/1176), roi artuqide de Mārdīn et de Mayyāfāriqīn. La traduction d'al-Malțī est perdue, mais celle de Mihrān existe dans un manuscrit unique en Iran, à Mashhad, dans la Bibliothèque de l'Imām 'Alī b. Mūsā al-Ridā. L'Introduction de cette traduction fut éditée par Salāh al-Dīn al-Munajjid (Muqaddimat kitāb al-hashä'ish wa-l-adwiya li-Dīsqūrīdis, bi-tarjamat Mihrān b. Manșūr b. Mihrān, Damas, 1965, 21-38). La comparaison de cette introduction à l'introduction de la MMA (Cf. Dubler, C. y Terés, E., La Materia Medica de Dioscórides. Transmision medieval y renacentista, vol. II: La version árabe de la Materia Medica de Dioscorides (texto, variantes e índices), Tetuan et Barcelone, 1952-1957 = alMaqā̄āt al-sab' (sic!) min kitāb Diyāsqūrìdūs wahwa hayūlā l-tibb fì l-hashā'ish wa-l-sumūm, 7-11), démontre que l'expression de Mihrān est plus correcte et plus claire que celle d' Iștifān.

${ }^{2}$ Dioscorides lui-même nous dit dans l'introduction de son livre «wa-qad allafnā hādhā al-kitāba fì khams maqālāt » (j'ai composé ce livre en cinq maqāla), MMA, $T$ [texte arabe édité], $8 ; K H$ [texte ms de Paris], 2 r. $^{\circ} ; W$ [l'édition du texte grec par M. Wellmann]: Dioscuridis, Pedanii Anazarbei, De Materia Medica. Libri Quinque, M. Wellmann (éd.), Berolini, 1907-1914, 1, 2 (ligne 19). La phrase est accompagnée dans $K H$ d'une glose illisible qui conteste l'attribution des maqāla VI et VII à Dioscorides. Une glose semblable du même auteur à la fin de la V'me maqāla $\left(K H, 131 \mathrm{v}^{\circ}{ }^{\circ}\right)$ fait la même remarque: "Avec la fin de cette V ${ }^{\text {ème }}$ maqāla, se termine le livre de Dioscorides, et ce qui va suivre après n'est pas de sa composition, mais il est surajouté (muqham) à son livre, je n'ai aucun doute sur ce fait, et j'ai déjà signalé cette même remarque au début du livre ».
} 
La rédaction du ms est terminée au mois de ramadan 616/novembre 1219. D'après une note qui suit immédiatement le titre de l'ouvrage sur le folio $1 \mathrm{r}^{\circ}$, on apprend que la rédaction a été exécutée à la demande (istansakhahā) du gouverneur de Damas Mubāriz al-Dīn Abū Ishạàq Ibrāhīm b. Mūsā, appelé «al-Mu'tamad» (démis de ses fonctions en 617/1220 et décédé en 623/1226). Mais cette copie a une relation directe avec la copie que possédait le grand pharmaco-botaniste andalou Abū 1-'Abbās Aḥmad b. Muḥammad al-Nabātī, de Séville, surnommé aussi Ibn al-Rūmiyyah (561/1165637/1239). Deux notes confirment bien cette relation: une sur la première page (f. $1 \mathrm{r}^{\circ}{ }^{\circ}$ ) affirmant que « Ce livre est collationné avec la copie d'Abū l-'Abbās al-Nabātī » (qūbila hādhā l-kitāb bi-nuskhat $A b \bar{\imath} l$-'Abbās al-Nabātì), et l'autre à la fin de la IV ème maqāla, rédigée par un certain 'Abd al-Malik b. Abī l-Fath al-Manbijī — qui pourrait être le copiste du ms - indiquant :

J'ai vu sur l'original avec lequel la collation est faite, le texte suivant concernant ces quatre maqāla: Abū 1-'Abbās Aḥmad b. Muḥammad b. Mufarrij al-Nabātī a noté qu'il les a confrontées deux fois avec des originaux différents et que leur texte a été trouvé conforme 3 .

On peut donc conclure que le ms est rédigé à Damas au mois de novembre 1219 à la demande de son gouverneur, et que l'original sur lequel il est copié est la copie personnelle d'al-Nabātī qu'il avait lui-même rédigée et collationnée avec des originaux différents de la $M M A$. Cela pourrait être confirmé en considérant deux faits : le premier est le passage d'al-Nabāti par Damas en 614/1217 pendant son grand voyage en Orient entre 612/1215 et 614/1217 aussi bien pour faire le pèlerinage à la Mecque que pour étudier la flore des régions islamiques visitées ${ }^{5}$; le deuxième est la très mauvaise écri-

${ }^{3}$ MMA (KH), 107 r. ${ }^{\circ}$ : « Shāhadtu 'alā al-aṣl al-mu 'āraḍ bihi mā șūratuhu fì hādhihi l-arba'i maqālāt: dhakara Abū l-'Abbās Ahmad b. Muhammad b. Mufarrij al-Nabātī annahu qābalahà bi-ușūl mutaghāyirat marratayn faṣaḥhat ».

${ }^{4}$ Cf. Jamāl al-Dīn al-Qifțî, Inbāh al-ruwāt 'alā anb̄āh al-nuḥāt, Muḥammad Abū 1-Faḍl Ibrāhīm (éd.), le Caire, 1950-1973, 4, 186-187. Il nous informe aussi qu'Abū 1'Abbās a été chez lui, dans sa maison, à Alep.

${ }^{5}$ On sait qu'il a enregistré ses observations botaniques dans un livre d'un grand intérêt scientifique intitulé "al-Rihla al-mashriqiyya » (Le Voyage oriental) que l'on nomme parfois «al-Rihlala al-nabätiyya » (Le Voyage botanique) aussi. Cf. par exemple Lisān al-Dīn b. al-Khațīb, Kitāb al-Iḥāta fì akhbār Gharnātạ, 'Abd Allāh 'Inān (éd.), Le Caire, 1973-1977, 1, 212. Nous ne connaissons de la matière de ce livre maintenant 
ture, de notre savant, bien connue ${ }^{6}$. Il nous est donc permis de supposer que, passant par Damas, Abū 1-'Abbās al-Nabātī aurait rencontré Mubāriz al-Dīn al-Mu'tamad, le gouverneur de Damas, auquel il aurait offert sa copie personnelle de la $M M A$ qui l'accompagnait pendant son voyage. Mais les grandes difficultés de lecture que causait la mauvaise écriture de son ms ont incité le gouverneur à demander aux savants de sa cour de lui faire une nouvelle copie d'une écriture claire est lisible. En effet, la graphie du ms est orientale, du type appelé neskhi.

En consultant le ms de la $M M A$ à la $\mathrm{BN}$ de Paris, en janvier 1980, puis, en utilisant un microfilm, dont nous avons fait un développement, en 1981, pendant la préparation de notre édition critique du Tafsīr kitāb Diyāsqūirīdūs d'Ibn al-Baytạā, nous avons bien constaté ce que L. Leclerc avait déjà remarqué avant nous :

L'écriture, de style oriental, est toute d'une main. Sans être élégante, elle est d'une facture large et très lisible. Les points diacritiques manquent parfois, mais se suppléent facilement. Les têtes de chapitre sont en gros caractères et en encre noire (...). Le corps du manuscrit est dans un assez bon état de conservation. Le haut des pages a été en partie envahi par l'humidité. Les marges, d'une largeur d'environ trois doigts, sont parfois complètement couvertes de notes précieuses, qui, malheureusement, sont quelquefois détruites soit par l'usure, soit par des bandes de papier appliquées pour soutenir le bord des feuillets. La reliure aussi, trop serrée, empêche d'en lire quelques — unes tracées sur les marges internes?.

Mais nous avons aussi constaté que le ms, à cause de son appartenance andalouse, a une double valeur.

La première valeur concerne l'édition critique de la $M M A$. En fait, pour leur édition du livre, C. Dubler et E. Terés se sont basés sur trois mss qu'ils ont choisis parmi d'autres : ceux de la BN de Madrid (de 512/1118) qu'ils ont utilisé comme texte original, de

qu'une centaine d'entrées données par Ibn al-Baytāar (le disciple d'al-Nabātī) dans son Traité des Simples, et c'est à partir de ces extraits que nous avons mis en valeur l'intérêt scientifique de ce livre. Cf. Ben Mrad, I., Buhüth fì tārikh al-țibb wa-l-saydala 'inda al-'arab, Beyrouth, 1991, 287-296.

${ }^{6} \mathrm{Ibn}$ 'Abd al-Malik al-Marrākushī nous dit dans son Kitāb al-Dhayl wa-l-takmila li-kitābay al-Mawsūl wa-l-Sila, M. b. Sharīfah (éd.), Beyrouth, 1964, 1, 512: «wa-kāna kathīra al-shaghaf bi-l-'ilm wa-l-du'ūb 'alā taqyīdih, 'alā ifrät radā'at khațtih » (Il avait une grande passion pour la science et pour la persévérance dans son enregistrement, en dépit de son écriture excessivement mauvaise).

${ }^{7}$ Leclerc, L., « De la traduction arabe de Dioscorides et des traductions arabes en général », Journal Asiatique, IX (1867), 5-38, 6-7.

Al-Qanțara (AQ) XXX 2, julio-diciembre 2009, pp. 581-622 ISSN 0211-3589 
l'Escorial (du $\mathrm{VI}^{\text {ème}} / \mathrm{XII}^{\text {ème }} \mathrm{s}$.), et notre $\mathrm{ms}$ de Paris, qui date de $616 / 1219^{8}$. Les comparaisons qu'ils ont faites entre les mss ont démontré que le ms de Paris est de loin le meilleur des trois. Mais, malgré cette différence de qualité, les éditeurs se sont contentés de transcrire le texte madrilène avec toutes ses lacunes et ses lectures défectueuses, et de mettre les corrections et les différences de lecture dans une longue section de 132 pages, intitulée "Variantes y Erratas $»^{9}$. Le grand nombre des variantes - qui sont souvent des lectures plus sûres ou des paragraphes entiers omis du ms de base - est puisé dans notre ms. Il y a même de graves lacunes que représentent surtout des omissions de chapitres tout entiers de la IV ${ }^{\text {ème }}$ maqāla. Les éditeurs ont relevé 30 chapitres omis qu'ils ont ajoutés dans cette section de "Variantes y Erratas $»^{10}$, auxquels nous ajoutons dix-sept autres chapitres qui ont échappé à leur attention et qui ne sont donc nullement mentionnés. Ce sont (les renvois aux chapitres dans le tableau suivant, se composent de trois chiffres : le n..$^{\circ}$ de la maqāla et le n. $^{\circ}$ du chapitre, liés par un tiret, puis le n..$^{\circ} \mathrm{du}$ folio de $K H$ ou le n. ${ }^{\circ}$ du volume et de la page de $W$ ):

${ }^{8}$ Cf. la description de ces mss dans MMA (T), VII-XII de l'Introd. Il y a d'autres mss dont les éditeurs n'ont pas connu l'existence et qui sont mentionnés après la parution de leur travail dans Sezgin, F., Geschichte des arabischen Schrifttums, Leiden, 1970, III, 59.

${ }^{9} M M A(T), 445-577$.

${ }^{10}$ Nous donnons, dans cette note, les titres des chapitres tels qu'ils sont transcrits dans $T=$ le texte arabe imprimé des $M M A$, avec le renvoi à la page, puis les origines

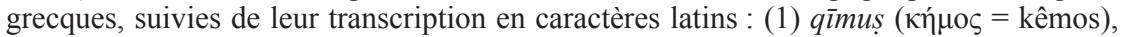
p. 553 ; (2) trīkhūmānis (

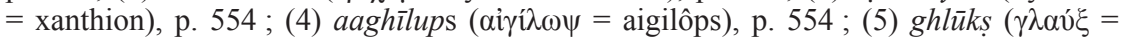

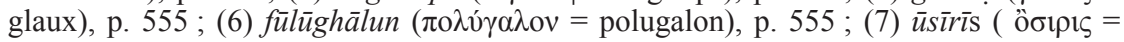
osiris), p. $555 ;(8)$ akhīnus (⿳亠㐅㐅㐅⿳亠丷厂 $\tau \rho \alpha \chi \varepsilon \check{c} \alpha=$ milax trakheia), p. 556 ; (10) milaqs layyā $(\mu \breve{\imath} \lambda \alpha \xi \lambda \varepsilon \dot{\varepsilon} \alpha=$ milax leia), p.

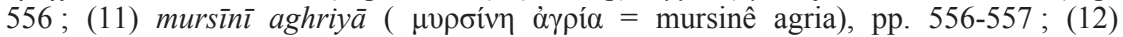

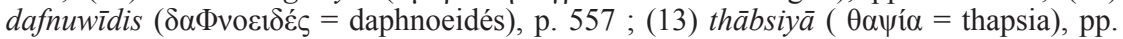

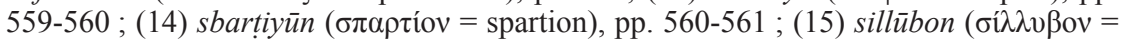

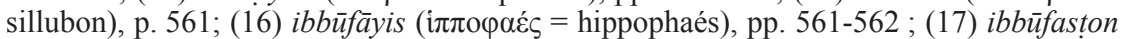

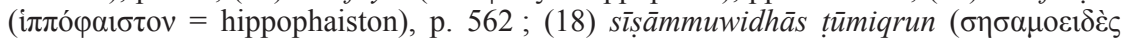

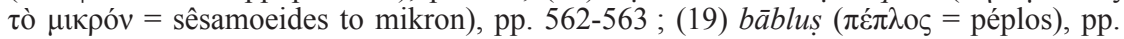

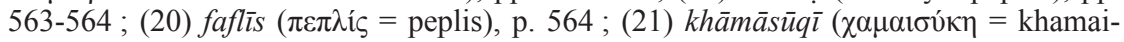

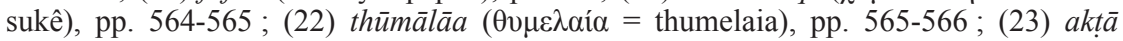

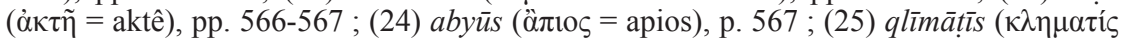

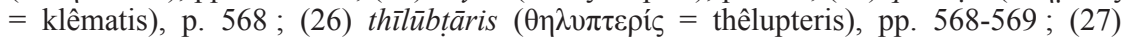

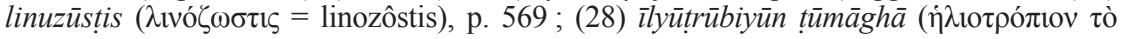

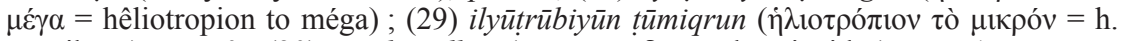
to mikron), p. $570 ;(30)$ squrbīwìdhās ( $\sigma \kappa \circ \rho \pi 10 \varepsilon 1 \delta \dot{\varepsilon} \varsigma=$ skorpioeidés $),$ p. 571. 


\begin{tabular}{|c|c|c|c|c|}
\hline $\begin{array}{l}\text { Terme } \\
\text { de KH }\end{array}$ & $\begin{array}{l}\text { Chap. } \\
\text { et f } \mathrm{f}^{\mathbf{0}}\end{array}$ & $\begin{array}{l}\text { Terme } \\
\text { de } W\end{array}$ & Transcription & $\begin{array}{l}\text { Chap. } \\
\text { et page }\end{array}$ \\
\hline d"̄ruqniyūn & $4-69,90 \mathrm{r}^{\circ}$ & 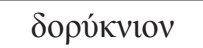 & doruknion & $4-74,2 / 233$ \\
\hline aaqūnītun & $4-71,91 \mathrm{r}^{\circ}$ & 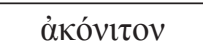 & akoniton & $4-76,2 / 237$ \\
\hline qunyūn & $4-72,91 \mathrm{r}^{\circ}$ & 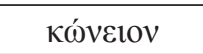 & kôneion & $4-78,2 / 239$ \\
\hline smīlaqs & $4-73,91 \mathrm{r}^{\circ}$ & $\sigma \mu \check{\imath} \lambda \alpha \xi$ & smîlax & $4-79,2 / 241$ \\
\hline afūqūnun & $4-74,91 \mathrm{v}^{\circ}$ & 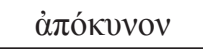 & apokunon & $4-80,2 / 241$ \\
\hline mirris & $4-110,95 \mathrm{r}^{\circ}$ & $\mu v \rho \rho i ́ \varsigma$ & & $4-115,2 / 266$ \\
\hline muāghrun & $4-111,95 \mathrm{v}^{\circ}$ & 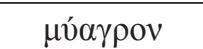 & muagron & $4-116,2 / 266$ \\
\hline iṣūfūrun & $4-115,95 \mathrm{v}^{\circ}$ & 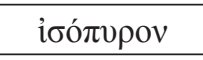 & isopuron & $4-120,2 / 269$ \\
\hline$q \bar{a} q \bar{a} l i y \bar{a}$ & $4-117,96 \mathrm{r}^{\circ}$ & $\kappa \alpha \kappa \kappa \alpha \lambda i ́ \alpha$ & kakkalia & $4-122,2 / 270$ \\
\hline būniyūn & $4-118,96 \mathrm{r}^{\circ}$ & ßov́viov & bûnion & $4-123,2 / 271$ \\
\hline fsūdūbūnyūn & $4-119,96 \mathrm{r}^{\circ}$ & $\psi \varepsilon v \delta$ oßov́vtov & pseudobûnion & $4-124,2 / 272$ \\
\hline khāmāqissus & $4-120,96 \mathrm{r}^{\circ}$ & 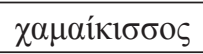 & khamaikissos & $4-125,2 / 272$ \\
\hline khāmāluqi $\bar{\imath}^{11}$ & $4-121,96 \mathrm{r}^{\circ}$ & $\chi \alpha \mu \alpha \imath \pi \varepsilon v ́ \kappa \eta$ & khamaipeukê & $4-126,2 / 273$ \\
\hline fūṭūmā & $4-123,96 \mathrm{v}^{\circ}$ & $\pi v ́ \tau \varepsilon v \mu \alpha$ & puteuma & $4-128,2 / 274$ \\
\hline ubughluṣsun & $4-124,96 \mathrm{v}^{\circ}$ & 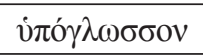 & hupoglôsson & $4-129,2 / 274$ \\
\hline anțirrīnun & $4-125,96 \mathrm{v}^{\circ}$ & 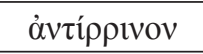 & antirrinon & $4-130,2 / 275$ \\
\hline 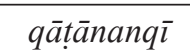 & $4-126,96 \mathrm{v}^{\circ}$ & 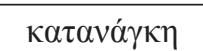 & katanankê & $4-131,2 / 276$ \\
\hline
\end{tabular}

Ces chapitres sont toujours inconnus des chercheurs qui ne disposent que du texte édité par Dubler-Terés (T). Ajoutés aux trente chapitres annexés par les éditeurs, et aux innombrables omissions de phrases et de paragraphes tout entiers qui constituent de vraies lacunes, ils requièrent ensemble une réédition vraiment critique de la $M M A$, se basant sur $K H$ en tant que texte original indispensable. En fait, issu d'un ms andalou appartenant au grand pharmaco-botaniste Abū 1-'Abbās al-Nabātī, qu'il a lui-même collationné et confronté deux fois avec des originaux différents, notre ms est un texte

${ }^{11}$ On constate ici la différence entre la lecture de $K H$ et la lecture de $W$. En fait, le terme grec est aussi écrit, dans quelques mss du texte grec de la $M M, \chi \alpha \mu \imath \lambda \varepsilon v ̉ \kappa \eta$ (khamaileukê), que l'on trouve dans $K H$, et cela confirme que les deux lectures sont attestées (Cf. les notes de Wellmann sur ce chapitre, et les notes de L. Leclerc sur sa traduction d'Ibn al-Bayțār, "Traité des Simples par Ibn El-Baïthar », dans Notices et Extraits des Manuscrits de la Bibliothèque Nationale et autres Bibliothèques, Paris, 1877-1883, tomes XXIII, XXV, XXVI, vol. 2, 3, § 737, où l'on trouve le terme écrit «khāmābūqī». Cf. aussi nos notes sur l'article «khāmāà̄qū » dans Ben Mrad, I., al-Muștalah al-a 'jamì fi kutub al-țibb wa-l-saydala al-'arabiyya, Beyrouth, 1985, 2, 347-348, § 817. 
précieux et d'une grande valeur pour une nouvelle édition critique complète du livre.

\section{Les gloses du ms}

C'est dans ces gloses - ou notes - que réside la deuxième valeur de $K H$. Ces gloses sont d'un très grand nombre, surtout dans les maqāla I-IV. Elles sont classables de différentes manières, qui démontrent leur richesse et leur valeur aussi bien botanique que terminologique. Leur classement pourrait, en effet, être :

(1) Chronologique, puisqu'elles appartiennent à diverses époques. On sait qu'elles sont écrites avant — ou peut-être simultanément avec - la rédaction de notre ms, mais aussi à des époques postérieures, surtout par quelques propriétaires du ms. L'antériorité - et la simultanéité - est un fait attesté par l'incorporation de quelques gloses à l'intérieur du texte, pendant la rédaction, dans de petits coins réservés. Ces gloses devraient exister dans l'original d'Abū l'Abbās al-Nabātî́12 et être transmises telles qu'elles sont par le copiste. La postériorité est aussi un fait confirmé par les gloses attribuées à Ibn al-Baytāar, puisées dans son Tafsīr kitāb Diyāsqūrìdūs, composé vers 623/1226, auxquelles nous nous réfèrerons plus loin.

(2) Graphique, puisque les gloses sont écrites au moins de trois mains différentes. Il y a, d'abord, le plus grand nombre de gloses qui remplissent les marges du ms et qui accusent la même graphie du corps du texte, et nous supposons qu'elles sont de la main du copiste, transmises de l'original d'Abū l-'Abbās al-Nabātī. Il y a ensuite des gloses d'une écriture très fine que l'on trouve sur les marges ou incorporées à l'intérieur du texte, comme les gloses évoquées précédemment. On y trouve souvent mentionnés les noms de Hun-

${ }^{12}$ C'est le cas, par exemple, de cette glose relative à l'identification de la plante

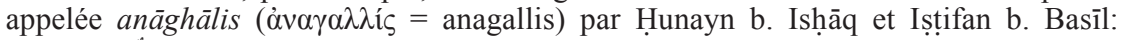

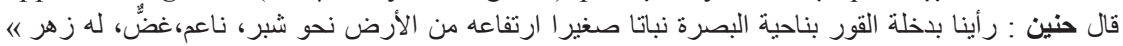

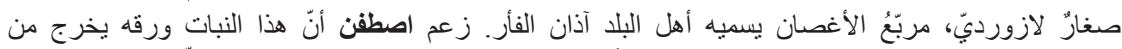

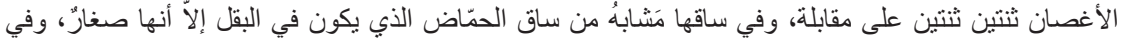

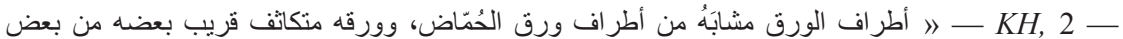
172, 53 v. ${ }^{\circ}$ Cf. aussi 3-29, 61 v. ${ }^{\circ}$, où l'on attribute à Isțtifān b. Basīl une identification de la plante appelée "ghalikhun" ( $\gamma \lambda \eta ́ \chi \omega v=$ glêkhôn $) ; 4-98,94$ r. ${ }^{\circ}$, où une note

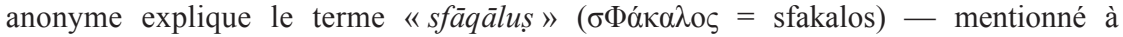
l'intérieur du chapitre — qui signifie « gangrène ». 
ayn b. Isḥāq et Iștifān b. Basīl. Puis il y a les gloses attribuées à Ibn al-Bayțār et qui sont ajoutées au ms par l'un de ses propriétaires. On peut facilement constater la ressemblance entre l'écriture de ces gloses et celle du tamlikk figurant sur la première page, portant les noms de Ahmad b. Abī Bakr Muhammad b. 'Asj (?) et de son fills Yahyā, et il paraît que c'est par la main de ce Yahyā — qui s'est approprié du ms après son père - que ces gloses sont écrites.

(3) Selon la position du terme annoté dans le texte. En fait, il y a des gloses qui se rattachent aux termes-entrées, c'est-à-dire aux titres des chapitres, et d'autres qui se rattachent à des termes qui figurent à l'intérieur du texte. Les premières commentent les termes clés de la $M M A$; quant aux autres, elles commentent soit l'identification d'une plante, soit l'un de ses aspects, tels que le volume du fruit, ou la couleur d'une variété, soit la signification d'un mot, etc. ${ }^{13}$.

(4) Thématique, puisque les gloses relèvent de plusieurs thèmes. Il y a, en effet, (a) des gloses pour identifier ou pour déterminer linguistiquement les termes grecs relatifs aux différents règnes de la nature, végétal, animal et minéral, décrits par Dioscorides, et ce sont les gloses les plus fréquentes; (b) des gloses pour expliquer ou pour définir un terme, ou pour déterminer son origine : son étymologie ou sa dérivation. Ces termes sont souvent grecs. C'est, par exemple, le

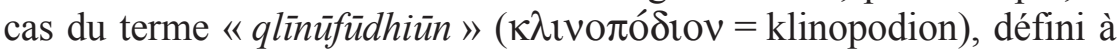
partir de sa dérivation: "qlinuüfüdhiūn est dérivé de qlīnī

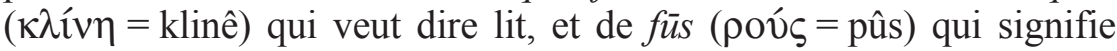
pied, c'est-à-dire 'le pied du lit' ». Cette plante est ainsi nommée, au dire d'Iștifān, " parce que sa fleur ressemble, d'après Dioscorides, à un pied de lit $»^{14}$; (c) des gloses pour commenter les lectures du texte, et surtout pour rectifier une transcription, ou pour faire une comparaison avec la lecture d'une autre copie de la $M M A^{15}$.

${ }^{13} \mathrm{Cf}$. dans les Hawāshī insérées à la fin de cette étude les $\S 14,17,31$, et 41 ; et

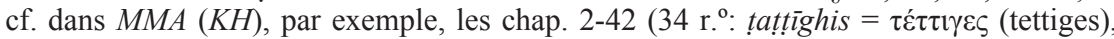
la cigale, donc un terme de zoologie), et 2-100 (43 r. ${ }^{\circ}$ : qiyāmus al-qibți $=\kappa v ́ \alpha \mu \circ$

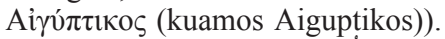

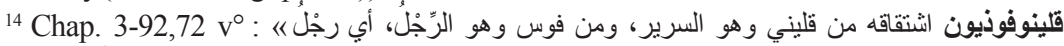

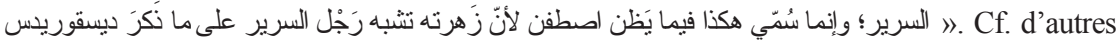
exemples dans : 3-81 (71 $\left.\mathrm{r}^{\circ}\right)$; 3-102 (73 v $)$; 3-140 (78 $\left.\mathrm{v}^{\circ}\right)$.

${ }^{15}$ Les nouvelles transcriptions proposées sont, elles aussi, souvent fautives. Parmi les innombrables comparaisons de lecture, nous mentionnons deux exemples: (1) en

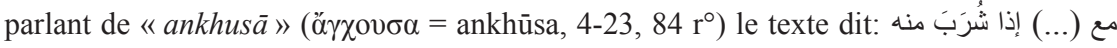


(5) Structurel, car les gloses n'ont pas la même structure. La plupart sont "simples », parce qu'elles ne présentent qu'une seule opinion ou observation d'un seul auteur. Mais on trouve aussi des gloses « composées » comportant deux opinions ou observations de deux auteurs différents; il y a même des gloses " complexes ", renfermant les observations de plusieurs auteurs. Les gloses composées présentent généralement les ajouts d'un auteur postérieur à un auteur précédent, soit pour donner une identification plus claire à une plante, soit pour donner de nouveaux équivalents aux termes grecs, ou, parfois, pour critiquer une opinion que l'on croit erronée ${ }^{16}$. Quant aux gloses « complexes ", qui sont rares, elles se composent de plusieurs éléments qui se succèdent, chronologiquement, dans le but d'approuver, de discuter ou de critiquer un élément précédent, ou d'ajouter de nouveaux éléments à la synonymie ou aux propriétés naturelles des plantes ${ }^{17}$.

(6) Par auteur, puisque de nombreuses gloses sont attribuées à leurs auteurs; et c'est ce genre de classement qui nous convient le mieux. Mais nous devons remarquer que nous allons nous limiter aux gloses andalouses relatives aux plantes, c'est-à-dire aux gloses botaniques d'origine andalouse.

\section{Les gloses andalouses}

Le premier qui s'est intéressé à ces gloses était L. Leclerc. Il les a classées en quatre catégories ${ }^{18}$. La $1^{\text {ère }}$ regroupe des gloses «d'une écriture très fine ", "l'autorité d'Etienne [Isțifān] y est presque constamment invoquée, et quelquefois celle de Honein »; la $2^{\text {ème }}$ porte en tête l'expression «lì»»; il l'attribue à Abū l-'Abbās al-Nabātī; la $3^{\text {ème }}$

الدواء الذي يقال له الزوفا والحُرْف أخرج الدودَ من البطن

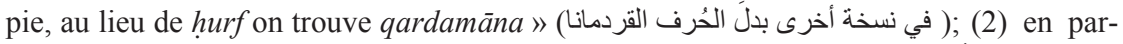

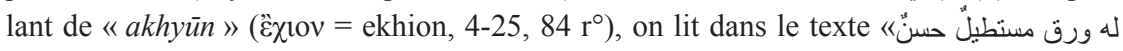
إلى إلى الدقة مَا هُو

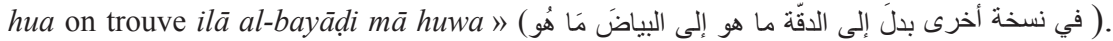

${ }^{16} \mathrm{Cf}$. des exemples de ces gloses «composées » dans les Hawāshī, § 16,18, 20, 22,25 et 26 .

${ }^{17}$ Le meilleur exemple, pour illustrer ce genre de gloses, est le $\S 44$ dans les Hawāshī, relatif au "farsāa » ( $\pi \varepsilon \rho \sigma \alpha i ́ \alpha=$ persaia) de Dioscorides, où l'on trouve une discussion concernant l'identification de cette plante à la plante appelée «labakh», et l'identification de «labakh» à l'«azädarakht». Cf. aussi les § 1 et 23.

${ }^{18}$ Leclerc, « De la traduction arabe de Dioscorides », 11-13. 
« se compose de citations d'Ibn al-Baytāa »; et la dernière comprend «toutes les autres notes qui n'accusent pas une origine commune». Nous avons repris, dans l'Introduction de l'édition que nous avons faite du Tafsīr d'Ibn al-Bayțār, ces quatre catégories avec quelques modifications ${ }^{19}$. En fait, elles sont de quatre grandes catégories :

La $1^{\text {ère }}$ regroupe les gloses précédées de l'expression « $l i \bar{l}$, dans lesquelles L. Leclerc voulait voir l'autorité d'Abū 1-'Abbās alNabātī. Il est, en vérité, légitime d'y voir l'œuvre du savant qui était à l'origine du $\mathrm{ms}$, puisque lui seul pouvait se donner le droit de s'attribuer des notes sur sa propre copie du livre, surtout s'il fut luimême le copiste. Mais rien ne nous permet d'être sûr de cette attribution, parce qu'on n'y trouve pas d'indice qui pourrait dévoiler l'identité du glossateur. Pourtant, les indices que nous trouvons surtout les observations portant sur la flore andalouse et sa terminologie - nous autorisent à affirmer qu'il est Andalou.

Nous avons relevé, des deux premières maqāla, douze gloses lisibles portant l'expression « $l \bar{l} »$, huit dans la $1^{\text {ère }}$, et quatre dans la $2^{2 \mathrm{eme}}$. Ces gloses se divisent en deux séries. Une première ayant le caractère identificatoire ou explicatif. C'est, par exemple, le cas de l'identification de "fîtūrā » $(\varphi \imath \lambda \hat{v} \rho \alpha=$ philura $)$ à « la troisième espèce du buxus dioica » (al-naw" al-thälith min al-katam al-jabalì $)^{20}$;

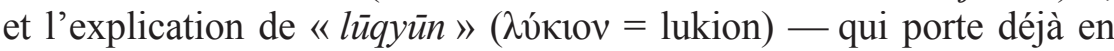
arabe le nom de hudad-par trois synonymes: "al-'awsaj alaswad », qui est arabe, "bashkābardīn» (?) qui est berbère, et «ashkîtshiyuh», qui est latin vulgaire (lațin̄i 'àmmì $)^{21}$. La deuxième série est d'un caractère critique. L'auteur reprend, en effet, des identifications ultérieures pour les critiquer en vue de les corriger, ou des traductions du texte grec pour les commenter en vue de les modifier. C'est, par exemple, le cas de la glose relative à la plante appelée

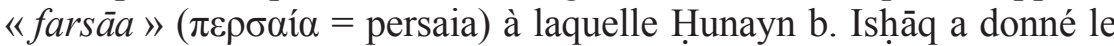
nom de «labakh» (mimusops), lui-meme identifié à «azädarakht» (melia azadarach) par Ibn Juljul. Celui-ci nous apprend, en effet, qu'il a posé la question à Abū Muhammad al-Baghdādī al-Kābūdī, qui a séjourné en Inde pendant plusieurs années, à propos de labakh,

${ }^{19}$ Ibn al-Bayțār, Tafsīr kitāb Diyāsqūrīdūs, I. Ben Mrad (éd.), Tunis et Beyrouth, 1990, Introduction, 69-72. Mais nous allons modifier encore un peu la catégorisation que nous avons adoptée dans l'Introduction au Tafsìr.

${ }^{20} \mathrm{Cf}$. les Hawāshī, § 25.

${ }^{21}$ Ibid., $\S 27$, et les notes qui l'accompagnent sur les termes berbère et latin. 
et que ce savant l'informa que cette plante est appelée azādarakht en persan $^{22}$. L'auteur de la glose s'oppose à cette identification :

Ibn Juljul dit cela, et c'est insignifiant (wa-laysa bi-shay'). L'arbre appelé labakh en Egypte est connu; on y mange son fruit, qui est doux, de saveur et d'odeur agréables, de couleur rougeâtre (ilā l-humratī mā huwa). Quant a l'azädarakht, il n'est pas ainsi, et il n'y a aucune ressemblance entre les deux plantes, parce que les feuilles de labakh ressemblent, chez nous, aux feuilles de l'abricotier dans la grandeur et dans la forme, mais il est plus lisse et de couleur blanchâtre (ilā l-bayādii). En comparant la grappe que porte le câprier, avec à l'intérieur, un noyeau de la grandeur d' une pistache, un peu long (ila attūili mā hiya), [on constate que] le fruit de l'azädarakht ressemble au [fruit du] câprier, dans la couleur et dans la forme. Il est doux et comestible ${ }^{23}$.

La $2^{\text {ème }}$ catégorie comprend des gloses que 1'on attribue facilement à Abū Dāwūd Sulaymān b. Hassān b. Juljul de Cordoue (m. ap. 384/994). Ces gloses sont de deux genres: le premier est constitué de gloses suivies de la lettre ج, l'initiale de «Juljul». Nous avons pu nous assurer de cette identification en comparant la matière de ces gloses avec les textes d'Ibn Juljul repris dans le Sharh anonyme ${ }^{24}$. Le deuxième genre est constitué de gloses non-signées. Nous avons pu les attribuer à Ibn Juljul parce que nous avons trouvé leurs traces, aussi, dans le Sharh anonyme, qui reproduit, souvent, le texte intégral du savant de Cordoue ${ }^{25}$. Le nombre total des gloses puisées

${ }^{22} \mathrm{Ibid}$, § 44; les propos d'Ibn Juljul lui sont attribués dans Sharh li-kitāb Diyāsqūrì̃ūs fì hayūlā al-țibb composé à la fin du $\mathrm{VI}^{\mathrm{e} m e} / \mathrm{XII}{ }^{\text {ème }} \mathrm{s}$. par un botaniste andalou anonyme $=$ Dioscurides Triuphans. Ein anonymer arabischer Kommentar (Ende 12. Jahrh. n. Chr.) zur Materia medica. Arabischer Text nebst kommentierter deutscher Übersetzung herausgegeben von Albert Dietrich, Gottingen, 1988 (1. Teil: Arabischer Text; 2. Teil: Übersetzung und Kommentar). L'auteur de ce Commentaire a repris presque la totalité de la matière du livre d'Ibn Juljul concernant le même sujet: Tafsìr asmä' al-adwiya almufrada min kitāb Dīsqūrīdūs. Nous avons abrégé dans nos renvois le Commentaire anonyme en Sharh, Chap. 1-110 (p. 38 dans le texte arabe). Le nom du savant irakien cité par Ibn Juljul est écrit dans le Sharh «al-Kāfūrī » au lieu d' «al-Kābūdī » que nous trouvons dans la glose. Mais nous n'avons trouvé ni Abū Muḥammad al-Kābūdī ni Abū Muhammad al-Kăfürī dans nos références biographiques.

${ }^{23} \mathrm{Cf}$. les Hawāshī, § 44.

${ }^{24}$ Cf. dans les Hawāshì les $\S 1,8,10,11,12,13,14,17,20,22,23,32,33,35,39$, 40, 41, 42, 43, 44. Dans le $\S 8$, la lettre ج est accompagnée de la lettre س س = (ج), et dans le $\S 10$ elle est accompagnée de $b$ (ج). Mais la signature est composée de quatre lettres dans le $\S 12$ ( ج ط س و ( ) déchiffrables.

${ }^{25}$ Ce sont des paragraphes puisés dans Tafsīr asmāa' al-adwiya al-mufrada min kitāb Dīsqūrīdūs d'Ibn Juljul. Cf. dans les Hawāshī les § 1, 2, 3, 13, 19, 21, 37. Cependant, on trouve aussi la lettre ج dans les $\S 1,2$ et 3. Elle ne renvoie pas à Ibn Juljul, mais au 
dans le Tafsīr d'Ibn Juljul est de 26 dans la seule première maqāla, et cela dépasse la moitié des 44 gloses lisibles que nous avons choisies et publiées de cette maqāla. Le thème principal de ces gloses est ce que L. Leclerc appelait "synonymie ${ }^{26}$, c'est-à-dire les Rapports de synonymie entre les termes grecs de la $M M$ et les équivalents arabes. Cela pourrait facilement s'expliquer par la nature même du Tafsìr d'Ibn Juljul, puisqu'il est consacré, comme son titre l'indique, à «expliquer » les termes grecs des médicaments simples de la $M M A$, c'est-à-dire à les commenter et à trouver, aux termes qui n'ont pas eu d'équivalents arabes, des solutions terminologiques.

La $3^{\text {ème }}$ catégorie se compose de gloses clairement attribuées à Abū Muḥammad 'Abd Allāh b. Aḥmad b. al-Bayṭār de Malaga (m. 646/1248). Comme nous l'avons supposé précédemment, ces gloses - qui sont, presque toutes, de la même écriture — sont de la main de l'un des propriétaires du ms, puisées dans le Tafsìr kitāb Diyāsqūrīdūs, rédigé par le botaniste de Malaga vers 623/1226 en Egypte, dans le but de combler les cases terminologiques restées vides dans la $M M A$. L'objet principal de ces gloses, comme celui des gloses se rapportant à Ibn Juljul, est la synonymie ou l'équivalence. Pour donner une idée claire et précise de l'abondance et de l'intérêt de ces gloses, nous nous référons aux cinquante trois (53) gloses que notre ms nous a fournies pour compléter notre édition du texte du Tafsìr de notre auteur, dont le ms unique existant à la Mecque est incomplet, parce qu'il s'arrête subitement au milieu de la IV ème maqāla. Les 53 gloses puisées dans notre ms $K H$, ont constitué 53 nouvelles entrées ajoutées au texte du ms unique : 21 à la $I^{\text {ème }}$ maquala, et 31 à la $\mathrm{V}^{\text {ème27}}$. Mais il est à remarquer que les gloses, d'après celles dont les textes existent déjà dans le Tafsìr, ne reproduisent pas l'intégralité du texte d'Ibn al-Bayțār. Le glossateur ne reproduit souvent que l'essentiel des entrées du Tafsìr, touchant surtout à la synonymie.

médecin grec Jālīnūs (Galien), lui-même auteur d'un livre sur les médicaments simples (Kitāb al-Adwiya al-mufrada). La mention de Galien est ajoutée par l'auteur de la glose parce que les textes d'Ibn Juljul ne font pas référence à l'auteur grec. Aussi devonsnous remarquer que la glose 13 est précédée de la lettre $\rightarrow$, que la 21 est suivie de la lettre $\dot{\boldsymbol{\rangle}}$, et ce sont peut-être les glosateurs qui ont rédigé les deux notes.

${ }^{26}$ Cf. Leclerc, «De la traduction arabe de Dioscorides », 12 ; idem, Histoire de la médecine arabe, Paris, 1876, 1, 237.

${ }^{27}$ Cf. Ibn al-Bayțār, Tafsīr, 307-322. 
La $4^{\text {ème }}$ catégorie réunit le reste des gloses, c'est-à-dire les gloses que l'on ne peut pas attribuer à une origine commune. Elles sont de deux genres :

(1) Des gloses signées, portant au début ou à la fin une lettre indiquant sûrement l'initiale du nom d'un auteur. Ces lettres pourraient aussi être des abréviations de noms d'auteurs utilisées par le copiste du ms andalou original, c'est-à-dire Abū 1-'Abbās alNabātī, pour abréger des références, de la même manière que nous avons vue en abrégeant le nom d'Ibn Juljul en ج. Parmi ces lettres, il y a une pourtant qui se répète : la lettre $\boldsymbol{0}$ que l'on trouve mentionnée quatre fois dans les deux premières maqāla ${ }^{28}$; mais toutes les gloses portant cette lettre ont un contenu qui reproduit ou qui se rapproche du Tafsir d'Ibn Juljul. C'est pourquoi elles portent, toutes, sur la synonymie. Pour donner des exemples de ces synonymes ou équivalents, nous citons les trois gloses suivantes de la deuxième

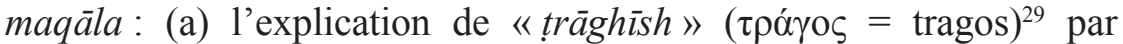
deux termes : un ancien emprunt arabisé : «sult», du latin spelta ${ }^{30}$, et un autre de l'arabe andalou : «jantīn $\bar{u} »$, du latin espagnol « centeno », du latin centenum ${ }^{31}$; (b) l'explication de «drāqunțiyūn» $(\delta \rho \alpha ́ k o v \tau i o v=\text { drakontion })^{32}$ par deux termes, l'un des deux, «șāruh», dans "s sāruh dhakar» (arum mâle), est emprunté au latin espagnol "sarrillo», qui a une relation directe avec le latin « arum $»^{33}$; l'autre terme est de l'arabe andalou : "khubz al-qurüd»

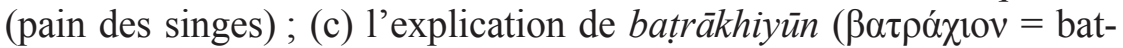

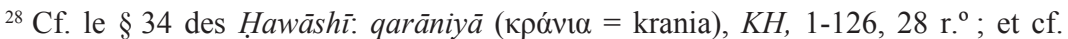

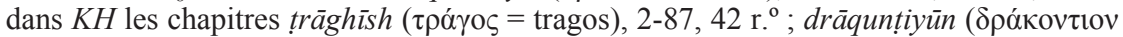

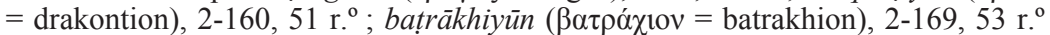

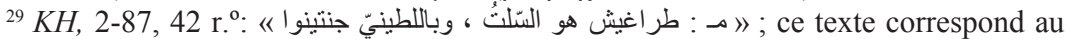
texte d'Ibn Juljul reproduit dans Sharh, 2-77, 49a.

${ }^{30} \mathrm{Cf}$. Ben Mrad, al-Muștalah al-a jamī, 2, 461, § 1081.

${ }^{31}$ Cf. Simonet, F., Glosario de voces ibericas y latinas usadas entre los mozarabes, Amsterdam, 1967, 159 (= Glosario) ; Corriente, F., A Dictionary of Andalusi Arabic, Leiden-New York-Köln, 1997, $104(=D A A)$; idem, « El roman andalusí reflejado por el Glosario botanico de Abulxayr ", in Estudios de dialectología norteafricana y andalusí, 5 (2000-2001), 93-241, 128 (=RGBA).

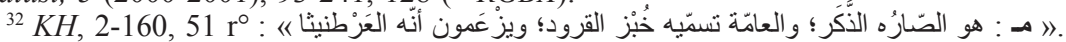

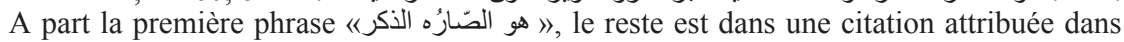
Sharh, 2-149, 63a, à Ibn Juljul.

${ }^{33} \mathrm{Cf}$. Ben Mrad, al-Mustalah al-a jamī, 2, 514, § 1221, à ajouter à ses références: Asín Palacios, M., Glosario de voces romances registradas por un botánico anónimo hispanomusulmán (siglos XI-XII), Madrid-Granada, 1943, 266, § 505 (=GVR); RGBA, 194. 
rakhion) ${ }^{34}$ par trois synonymes : le premier, "difda ' $\bar{\imath} »$, est une traduction littérale du terme grec ; le deuxième, kabikaj, est un emprunt au persan ${ }^{35}$ bien connu chez les auteurs arabes sur les medicaments simples ; quant au troisième, "ward al-hubb ", il a été déjà mentionné par Abū Bakr al-Rāzī (m. 313/925) dans le Hīāwī, puis repris par les auteurs postérieurs ${ }^{36}$.

(2) Des gloses complètement anonymes, mais nous croyons qu'il n'est pas difficile d'y trouver des traces du botaniste agronome Abū l-Khayr al-Ishbīlī (V-VI/XI-XII ${ }^{\text {èmes }} \mathrm{s}$.). Cependant, ce genre de gloses ne se limite pas à la synonymie. On y trouve, en effet, des éléments plus ou moins étendus portant sur la division des espèces et des variétés des plantes, leur identification et leur denomination, classique et dialectale andalouse. Pour illustrer ce genre, nous en proposons deux gloses :

(a) La première traite de la plante appelée bulbūs $(\beta o \lambda \beta o ́ \varsigma=$ bolbos):

Il y en a trois espèces : une sauvage, une de campagne et une cultivée, et elles sont toutes des espèces d'oignon. De l'espèce cultivée il y a une variété amère et une autre de saveur douce. De celle-ci, il y a une sous-variété à écorce rouge que nos herboristes (shajjārūnāa ${ }^{37}$ appellent $m \bar{a} g h a r u h^{38}$. De la variété amère, il y a une sous-variété à écorce blanche, qui ressemble à la scille (basal al-ishqill) dans sa forme et non pas dans sa couleur. La troisième espèce a des fleurs blanches et des feuilles qui ressemblent à celles du nénuphar cul-

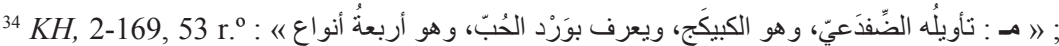
une autre glose anonyme qui suit immédiatement la précédente indique qu'il s'agit en fait de la plante appelée kaff al-sabu“ (la renoncule) : "هذا هو كفَ النَُّع إ). Le contenu des deux gloses se trouve dans le Sharh, 2-158, 66a, mais la division en quatre espèces n'est pas mentionnée dans le texte d'Ibn Juljul.

${ }^{35}$ Cf. Ben Mrad, al-Mustalah al-a jamī, 2, 659-660, § 1593.

${ }^{36}$ Cf. par exemple Abū l-Rayḥān al-Bīrūnī, Kitāb al-Ṣaydana fì l-țibb, A. Ziryāb (éd.), Tehran, 1991, 421, § 1074; Abū 1-Khayr al-Ishbīìi, Kitāb 'Umdat al-țabìb fì ma'rifat al-nabāt li-kulli labīb, J. Bustamante, F. Corriente et M. Tilmatine (éd. et trad.), Madrid, 2004 et 2007, 575a., 761t., §5020.

37 «Herboristes » est l'équivalent de "'ashshābūn» dans la littérature botanique arabe ; mais le terme «shajjär» (pl. shajjärün) est utilisé aussi comme synonyme. Cf. par exemple l'introduction d'Ibn al-Bayțār à son Tafsìr, 109 (ligne 9).

${ }^{38}$ Abū l-Khayr al-Ishbīlī lui a consacré une entrée dans son Kitāb 'Umdat altabīb, 333-334a, 466-467t, §3003 ; et le même auteur le considère (p. 93a, ligne 24, $150 \mathrm{t}, l .3$, § 985) comme $a$ 'jamī, c'est-à-dire latin espagnol. M. Asín Palacios dans son GVR (159-160, §313), lui propose comme étymologie latine macer, mais F. Corriente propose dans son $R G B A, 155$, une autre étymologie latine : Megarus, de $\mathrm{Me}$ gara.

Al-Qanțara (AQ) XXX 2, julio-diciembre 2009, pp. 581-622 ISSN 0211-3589 
tivé (nīnüfar bustānì). Elle a un oignon ayant la couleur du oignon comestible (bașal al-akl). Nos herboristes lui donnent le nom de mägharuh ${ }^{39}$.

Abū 1-Khayr, dans son 'Umdat al-țabìb, mentionne lui aussi trois espèces de bulbūs, mais en se référant à Dioscorides : une espèce de campagne (rîfi) et une espèce sauvage (barri) qui ne sont pas utilisées (humā ghayr musta 'malayn), et une espèce comestible (ma'kūl), utilisée, qu'il subdivise en deux variétés : une douce aux écailles rouges, et une amère aux écailles blanches. Il leur ajoute une troisième variété qu'il appelle māgharuh ${ }^{40}$.

(b) La deuxième glose porte sur la plante appelée mälīlūtus $(\mu \varepsilon \lambda \hat{\imath} \lambda \omega \tau \mathrm{\sigma} \varsigma=$ melilôtos), qui est le mélilot (iklïl al-malik) :

Il y a des savants qui l'identifient à la plante appelée qurniuj $j^{41}$, et il n'en est pas ainsi. En effet, il y en a deux espèces de mélilot : l'une a des feuilles qui ressemblent à celles du fenugrec (hulba) ou à celles de la luzerne (nafal); leur odeur est semblable à celle des feuilles du figuier avec un peu d'arome. Elle a des fleurs jaunes et fines, et chacun de ses rameaux porte à son extrémité une couronne ( $\mathrm{iklill}$ ) ayant une forme pareille à un demi-cercle, arrondi, contenant des graines pareilles à celles du fenugrec dans la forme et la couleur, sinon qu'elles sont considérablement plus petites. Cette espèce est connue chez les botanists sous le nom de qurt $t^{42}$, un nom que porte aussi la plante appelée handaqūqā (trèfle), mais qui n'est pas le mélitot que nous

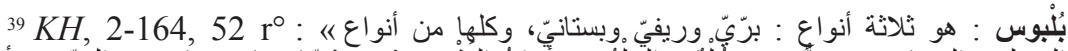

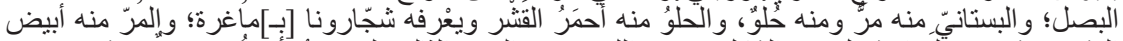

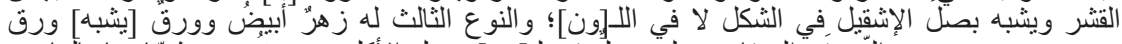

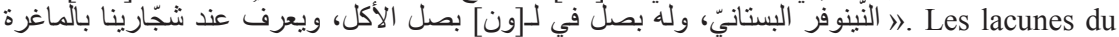
texte sont dues à la photographie du microfimm du ms; elles sont remplies à l'aide du texte de 'Umdat al-țabïb.

${ }^{40}$ Abū 1-Khayr, 'Umdat al-tabìb, 93a, 149-150t, § 985.

${ }^{41}$ Le terme est mentionné par 'Abd Allāh b. Șālah dans Sharh (3-40, p. 85a, et p. $389 \mathrm{t}$ ) sous la forme de «qurunaj» (selon la « voyellation » d'A. Dietrich) pour désigner deux espèces (parmi quatre) de mélilot. Il est aussi mentionné par Ibn al-Bayțār (Tafsìr, 3-38, 226), sous la forme «qurnaj » pour désigner deux espèces de mélilot (parmi quatre également). Il est mentionné pareillement par Abū 1-Khayr ('Umdat altabīb, 43 et $44 \mathrm{a}, 67$ et $68 \mathrm{t}, \S 551$ ) mais sous la forme «qurnūlluh», pour désigner le mélilot en général, après avoir douté, au début du paragraphe, de cette désignation. Il s'agit d'un terme emprunté au latin, dont l'origine est « cornus ». Cf. DAA, 425-426; $R G B A, 188$.

${ }^{42}$ Le terme est transcrit deux fois qaraz dans le texte, et c'est une fausse transcription, parce que le qaraz désigne la plante appelée " akākiā» (acacia) qui porte en arabe le nom de «sanț» aussi. Quant au terme qurț, on sait qu'il désigne le handaqūqa (trèfle) et une autre plante qui s'appelle «barsim » en arabe, qui est, paraît-il, le mélilot dont parle Ibn al-Bayțār dans Kitāb al-Jāmi ' li- mufradāt al-adwiya wa-l-aghdhiyah, Būlāq (éd.) [= b], 1291/1874, 1, 50, et Traité des Simples (trad. de L. Leclerc), 1, 
avons décrit. L'autre espèce a des feuilles pareilles aux feuilles du pois chiche (himmaș) aussi bien dans la forme que dans la grandeur. Elles sont sur des tiges nombreuses, grêles, arrondies, qui s'étalent sur la terre, d'un empan environ. Elle a aussi des fleurs jaunes et fines, [et des graines jaunes] mais aussi des [graines] blanches. Quand ces graines tombent, de petites couronnes grêles comme une bougie $(m \bar{l} l)$, semblables à des demi-cercles et [ressemblant à] des bracelets de [petits] enfants, prennent leur place à l'extrémité de [chaque] tige. Desséchées, elles deviennent jaunes, renfermant de petites graines de couleur jaune, pareilles aux graines du fenugrec aussi, aussi bien dans la forme que dans la couleur, sinon qu'elles sont beaucoup plus petites. Les deux espèces sont utilisées en médecine ${ }^{43}$.

Les traces d'Abū 1-Khayr sont très visibles dans cette glose. Lui aussi il mentionne deux espèces de mélilot; mais il subdivise la première en quatre variétés, et la deuxième - qu'il appelle qurnülluh, de la meme famille étymologique que qurnüj, mentionné par notre glossateur - en trois variétés ${ }^{44}$. Des phrases tout entières sont identiques dans les deux textes, et, grace à cette resemblance, il nous a été possible de combler des lacunes, dans la glose, causées par la photographie du microfilm et par l'humidité qui a envahi le haut de la page ${ }^{45}$.

\section{De l'apport terminologique des gloses botaniques}

Nous avons remarqué que les gloses synonymiques sont les plus nombreuses dans le ms. Trois facteurs sont à l'origine de cette abondance: (a) l'introduction massive de gloses puisées dans le

118, § 128t. Il lui consacre même une entrée : «qurțt»,4/15b, 3/77, § 1759t. Leclerc l'identifie au Trifoloium Alexandrinum.

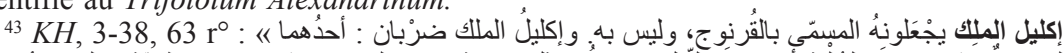

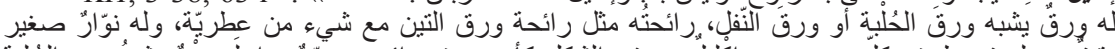

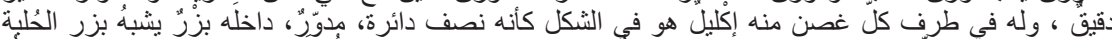

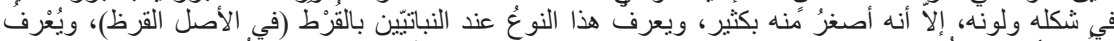

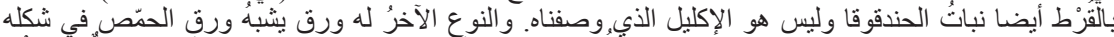

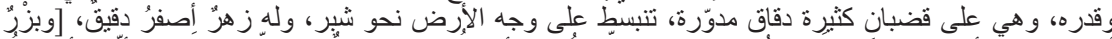

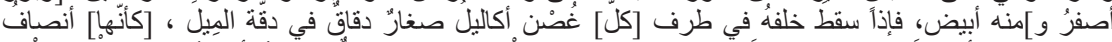

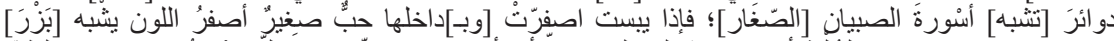

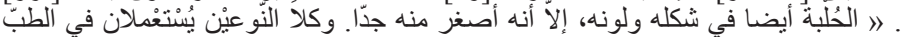

${ }^{44}$ Cf. Abū 1-Khayr, 'Umdat al-țabïb, 43a, 67-68t, §551.

${ }^{45}$ Le texte d'Abū l-Khayr nous a permis d'ajouter au texte de la glose les expressions qui lui manquent, aussi bien dans la traduction que dans le texte lui-même, reproduit dans la note (43).

Al-Qanțara (AQ) XXX 2, julio-diciembre 2009, pp. 581-622 ISSN 0211-3589 
Tafsìr asmā' al-adwiya al-mufrada min kitāb Dīsqürìdūs d'Ibn Juljul ; (b) l'introduction massive de gloses attribuées à Ibn al-Bayțār et puisées dans son Tafsìr kitāb Diyāsqūirìdūs, (c) l'intérêt que portaient les auteurs des autres gloses aux questions des équivalences. Par cet aspect, les gloses botaniques de notre ms s'inscrivent dans un mouvement terminologique très large, connu, surtout en Andalousie, pendant les IV/X-VII/XIII ${ }^{\text {èmes }} \mathrm{s}$., et consacré à la révision (muräja 'a) et au commentaire (sharh) de la $M M A$, et particulièrement à l'explication (tafsir) de ses termes grecs restés sans équivalences arabes, en leur donnant des équivalents ${ }^{46}$.

Une révision «directe» et quatre commentaires andalous consacrés à la $M M A$ constituent l'essentiel de ce mouvement. La révision est faite à Cordoue, à l'aide d'une copie du texte grec de la $M M A$, reçu par le calife umayyade 'Abd al-Raḥmān al-Nāṣir (300/912-350/961), de l'empereur byzantin de l'époque, en 337/948. Le travail de révision qu'ont fait les médecins de la cour du calife s'est réalisé avec l'appui d'un moine nommé Nicolas (niqūlā l-rāhib), ayant connaissance aussi bien du grec que du latin, et que l'empereur byzantin envoya en 340/951 à Cordoue, à la demande du calife andalou. Résumant les efforts de ces savants, Ibn Juljul nous rapporte :

Grâce aux recherches de ce groupe de médecins sur les noms et l'identification des simples du livre de Dioscorides, en Andalousie et particulièrement à Cordoue, on parvint à déterminer, à reconnaître ces simples et à bien prononcer leurs noms sans commettre d'erreurs, de telle sorte qu'il ne resta plus de doute à leur sujet, à l'exception d'un petit nombre de simples sans importance, environ une dizaine ${ }^{47}$.

\footnotetext{
${ }^{46}$ Nous avons consacré une étude tout entière à cette question: Cf. Ben Mrad, I., «Fī manhajiyyat naql al-"ulūm al-a jamiyya ilā l-'arabiyyah: intiqāl "maqālāt" Diyūsqirīdīs ilā 1-thaqāfa al-'arabiyya: tarjamatan wa-murāja'atan wa-sharḥan » ("De la méthodologie de transmission des sciences étrangères à la langue arabe : la transmission de la Materia Medica de Dioscorides à la culture arabe: traduction, revision et commentaire »), in Hawliyyāt al-jāmi 'a al-tūnisiyya, 24 (1985), 247-291, repris, remanié, dans Ben Mrad, I., Dirāsāt fì l-mu 'jam al- 'arabī, Beyrouth, 1987, 227-270. Les renvois que l'on fera à cette etude dans les notes suivantes sont à cette édition de Dirāsāt. Nous notons que le même thème a été traité dans le Chap. II de notre Introduction à l'édition du Tafsīr d'Ibn al-Baytār, 42-55.

${ }^{47}$ Cf. Abū 1-'Abbās Aḥmad b. Abī Ușaybi'a, 'Uyūn al-anbā' fì Ṭabaqāt al-ațibbāa', A. Müller (éd.), le Caire, 1299/1882, 2, 47-48; Leclerc, L., «Études historiques et philologiques sur Ebn Beïthâr », Journal Asiatique, XIX (1862), 433-461, 439-441 ; idem, Histoire de la médecine arabe, 1, 237-238 et 430-431 ; Meyerhof, M., «Die Materia Medica des Dioscurides bei den Arabern », Quellen und Studien zur Geschichte
} 
Cette « révision » n'est nullement une nouvelle traduction, parce que le travail des savants andalous se limitait à la recherche des équivalents arabes aux termes grecs restés sans équivalents dans la $M M A$. De même, le ms de Paris qui fait l'objet de notre étude (notre $K H$ ) n'est nullement une copie de cette révision, comme le croyait M. Meyerhof ${ }^{48}$.

Les commentaires sont des shuruḥ et des tafāsìr rédigés par des Andalous entre le IV/ $\mathrm{X}^{\text {ème }}$ et le VII/XIII ${ }^{\text {ème }} \mathrm{s}$. Les sources bibliographiques nous parlent de quatre commentaires: (a) Tafsìr asmä' al-adwiya al-mufrada min kitāb Disqūrìdūs d'Ibn Juljul (m. ap. $384 / 994)^{49}$, qui est, sûrement, le fruit de la révision andalouse de la MMA; (b) Sharh adwiya Diyāsqūrīdūs wa-Jālīnūs wa-l-tanbīh 'alā awhām mutarjimīhā ou Tafsìr asmā' al-adwiya al-mufrada min kitāb

der Naturwissenschaften und der Medizin, 3 (1933), 72-84, 75-76; idem, « Esquisse d'histoire de la pharmacologie et botanique chez les musulmans d'Espagne », Al-Andalus, 3 (1935), 1-41, 8-11 ; Vernet, J., La cultura hispano-árabe en Oriente y Occidente, Barcelona, 1979, 70-71 ; idem, Ce que la culture doit aux Arabes d'Espagne, G. Martínez Gros (trad.), Paris, 1985, 82-84 ; Ben Mrad, Dirāsāt, 238-239.

${ }^{88} \mathrm{Cf}$. Meyerhof, «Esquisse d'histoire », 11, où il affirme : «Quant à la correction "espagnole" de la traduction de Dioscoride, Leclerc en a étudié l'exemplaire unique qui se trouve dans la Bibliothèque Nationale à Paris sous le n. ${ }^{\circ}$ Suppl. 1067 (2849); il est couvert de notes marginales qui contiennent les synonymes arabes des noms grecs et beaucoup de noms de la langue espagnole vulgaire et de dialectes berbères de l'Afrique du Nord ». Meyerhof fait allusion ici à l'étude de L. Leclerc publiée dans le $J A$ en 1967 , mentionnée précédemment dans la note (7), et particulièrement aux « gloses » qui remplissent le ms. Il les considère, parait-il, comme des " corrections » des « réviseurs » andalous dont parlait Ibn Juljul. En fait, Leclerc n'a nullement fait de relation, dans son étude, entre ce ms de Paris de la $M M A$ et la révision andalouse. Il a même bien indiqué (pp. 6-7) la date de l'écriture (616/1219), la collation des originaux du ms par Abū l-'Abbās al-Nabātī (p. 7), et l'origine orientale du ms. Toutefois, Leclerc lui-même s'est mépris en croyant (pp. 7-8) que le ms «est allé de l'orient à l'occident, [puisque] la plupart des notes ayant été faites en Espagne». Il s'est basé, en affirmant que le ms est allé de l'Orient en Occident, sur l'existence de l'un des ses propriétaires à Constantinople. Nous lisons, en effet, sur le folio 1 r. $^{0}$ : " ملكس " محمد [بن] محمد القوصوني لطف الله به وبالمسلمين في سنة 971 [=. Ce Qawșūnī est un médecin turc du X/XVI s. bien connu, et Leclerc a dû constater de la date (971/1563) que porte le tamlikk qu'il serait impossible de voir le ms, après cette date, voyager de la Turquie en Espagne pour qu'on y mette les gloses qu'il porte, après le $\mathrm{X} / \mathrm{XVI}{ }^{\text {ème }}$ s., comme si l'Andalus aux XVI-XVII ${ }^{\text {èmes }}$ s. était toujours le même Andalus du XII-XIII ${ }^{\text {èmes }}$ s., l'époque des grands botanistes arabophones, tels que Abū l-Khayr al-Ishbīlī, Abū 1-'Abbās al-Nabātī et Ibn al-Bayțār de Malaga.

${ }^{49}$ Le Tafsir d'Ibn Juljul est encore inédit. Il existe dans deux mss : celui de la BN de Madrid (n. ${ }^{\circ} 4981$, contenant une partie de la $3^{\text {ème }}$ maqāla, toute la $4^{\text {ème }}$, et une partie la $5^{\text {ème }}$ ), et celui de Teheran (Majlis Shuray Milli, n. ${ }^{\circ}$ 1538, qui contient, parait-il, tout le texte). Le texte des quatre premières maqāla est reproduit intégralement dans le Sharh anonyme.

Al-Qanțara (AQ) XXX 2, julio-diciembre 2009, pp. 581-622 ISSN 0211-3589 
Dīsqūrīdis d'Abū 1-'Abbās al-Nabātī (m. 637/1239) ${ }^{50}$; (c) Tafsìr kitāb Diyāsqurīdūs d'Ibn al-Bayțār, dont nous avons édité le texte; (d) Sharh fì kitāb Diyāsqūrīdūs d'Abū 1-Hasan 'Alī b. 'Abd Allāh alIwarkī, surnommé Ghulām al-Hurrah ${ }^{51}$. Nous avons déjà fait l'étude détaillée de l'apport terminologique de deux de ces commentaires: les Tafsìr d'Ibn Juljul et d'Ibn al-Bayțā̄ ${ }^{52}$.

L'objectif principal de tout ce mouvement était donc de trouver les équivalents arabes aux termes grecs de la $M M A$, pour combler les cases terminologiques restées vides dans la traduction baghdādienne. Notre ms, avec les gloses botaniques qui le remplissent, s'inscrit pleinement dans ce mouvement. En effet, le souci essentiel des glossateurs était de parvenir à déterminer les termes grecs du livre, soit en leur trouvant des équivalents arabes, soit en élargissant la terminologie arabe déjà établie, en donnant de nouveaux termes synonymes. On peut donc le compter, grâce à ses gloses andalouses, parmi les révisions «directes », bien que la révision fût faite par plusieurs glossateurs; on peut également le considérer comme l'un des « commentaires », puisqu'il contient surtout les résultats des recherches de deux grands commentateurs de Diosciorides: Ibn Juljul et Ibn al-Baytār, auxquels s'ajoutent les recherches des commentateurs anonymes.

${ }^{50}$ Le $1^{\text {er }}$ titre est mentionné par Ibn 'Abd al-Malik al-Marrākushī, al-Dhayl, 1, 513,

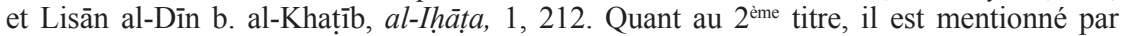
Ibn Abī Ușaybi'a dans 'Uyūn al-anbā', 2, 81. A. Dietrich voulait y voir le Sharh anonyme qui existe en ms à Istanbul (Nuruosmaniye, n. $.^{\circ} 3589 / 10$, f. 80 v. ${ }^{\circ}-129$ v. ${ }^{\circ}$ ), rédigé au Maroc - à Marrākush - vers 583/1187, et dont il a édité le texte et traduit en allemand (Cf. Dietrich, A., EI , 1982, Supp., 397 ; idem, Introduction au Sharh, 44-46). Deux noms se répètent dans ce Sharh : celui d'Ibn Juljul dont l'auteur anonyme se réfère au texte de son Tafsìr au début de chaque chapitre, et celui de 'Abd Allāh b. Șālạ̣ al-Kutāmī, qui était, avec Abū 1-'Abbās al-Nabātī, l'un des maîtres d'Ibn al-Bayțār.

${ }^{51}$ Il est mentionné par Ibn 'Abd al-Malik al-Marrākushī, al-Dhayl, I. 'Abbằs (éd.), Beyrouth, 1965, 5, 239, dans une courte notice biographique qui nous informe que l'auteur - Abū l-Ḥasan Ghulām al-Hurra - avait une participation positive en médecine et en botanique, qu'il a composé un commentaire sur la $M M A$, dans lequel il a pu vérifier beaucoup de noms des plantes de Dioscorides, aidé par sa captive Anna la Grecque (Ānna al-ghariqiyya). On trouve les traces de cet auteur dans des gloses qu'il a rédigées sur le $1^{\text {er }}$ volume du ms de Madrid de 'Umdat al-tabīb d'Abū l-Khayr, et qui sont reproduites presque intégralement dans l'édition madrilène du livre.

${ }^{52}$ Ben Mrad, Dirāsāt, 247-264. D'autres détails sur l'apport d'Ibn al-Bayțār sont donnés dans notre Introduction à son Tafsìr, 74-91. Cf. aussi sur le Tafsìr d'Ibn Juljul et sur le Sharh anonyme Ben Mrad, I., al-Mu 'jam al-ilmī al- 'arabi al-mukhtaṣs hattā muntașaf al-qarn al-h̄ādì 'ashar al-hijrī, Beyrouth, 1993, 56-61. 
Cette relation directe entre "l'effort terminologique » que représentent les gloses botaniques du ms de Paris et le travail élaboré par Ibn Juljul puis par Ibn al-Bayțār, met en évidence, en vérité, la similitude entre les approches des deux auteurs andalous en commentant la terminologie botanique de la $M M A$, et l'approche que décèlent les gloses, basées essentiellement sur la synonymie.

Pour donner une idée succinte sur cette approche, nous allons jeter un regard rapide sur les "niveaux de langue » qui constituent les gloses synonymiques de la première maqāla. Quatre niveaux sont bien apparents dans ces gloses. Le $1^{\text {er }}$ est l'arabe classique. Il s'agit de termes puisés dans le fonds lexical arabe classique, le fașīh. Ils sont au nomre de treize $\mathrm{e}^{53}$; mais la plupart de ces termes sont de vrais synonymes des termes arabes déjà existants dans la $M M A$. Seuls

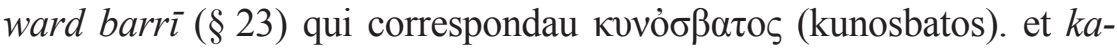
tam jabali, 'utum et zaghbaj (§ 25) qui correspondent au $\varphi \imath \lambda u ́ \rho \alpha$ (philura) de Dioscorides, sont nouveaux. Le $2^{\text {ème }}$ niveau est représenté par les néologismes, c'est-à-dire les termes appartenant aux fonds lexical appelé muwallad parce qu'il ne figure pas dans le fonds classique, appelé fașịh. Ces néologismes ne sont pas nombreux parce qu'on n'y trouve que sept $\mathrm{t}^{54}$. Ils sont tous des termes composés, et un seul parmi eux est créé par traduction littérale : le 'ullayq al-kalb (\$23) qui calque ou traduit littéralement l'équivalent grec кvvỏ $\beta \alpha \tau o \varsigma$ (kunosbatos). Pourtant, la plupart de ces néologismes pourraient bien faire partie du $3^{\text {ème }}$ niveau : le dialectal. Le $3^{\text {ème }}$ niveau est donc le dialectal, ou 'ámmī, qui occupe dans les gloses une place semblable à celle du fasịh : douze termes appartiennent, en effet, à ce niveau, dont huit sont de l'arabe andalou ${ }^{55}$, et quatre issus d'autres dialectes ${ }^{56}$. Ce-

${ }^{53}$ Ce sont muql azraq (§ 13), 'ilk al-anbāt et dirw (§ 16), ward barrī (§ 23), riqān et sa variante raqūn (§24), katam jabali, 'utum et zaghbaj (§25), kaff jadhmä' et faqad (§28), qasb (§30) et hamät $(\S 41)$. Nous les considérons comme classiques parce qu'ils se trouvent dans les dictionnaires de l'arabe classique, particulièrement dans Kitāb al-Nabāt d'Abū Hanīfa al-Dīnawarī. Ces termes sont généralement commentés dans nos notes sur les Hawāshī, c'est pourquoi nous nous limitons ici au renvoi aux numéros des $\S$.

${ }^{54}$ Ce sont sunbul rūmī (§ 6), sunbul jabalī (§ 7), qātil al-dhi'b (§ 11), 'awsaj aḥmar (§ 22), 'ullayq al-kalb (§23), 'awsaj aswad (§ 27) et shajarat ibrāhim (§ 28).

${ }^{55}$ Ce sont jillitit (§ 17), sufayrā' $(\S 20)$, tūz (§ 21), țurnīn (§ 32), mushtahā (§33), baqūrniyh (§ 36) qui est, paraît-il, un emprunt au latin espagnol «bigornia », du latin « bicornus », dhukkār (§ 42) et lakhshiyah (§ 43).

${ }^{56}$ Les qutre autres termes appartiennent aux dialectes maghrébin (habb al-mulūk, $\S 32$ ), syrien (yaranna', §24), et égyptien (shajarat Maryam et shajara §28). 
pendant, bien que l'un des termes - lakhshiya (§ 43) — soit étiqueté dans la glose comme dialectal (tusammīh al- 'àmma), il appartient en vérité au $4^{\text {ème }}$ niveau : les emprunts, parce qu'il est du latin espagnol « lexia », du latin « lixivia »; mais, comme il arrive souvent, que les néologismes et les dialectalismes s'interfèrent, dans les ouvrages arabes des médicaments simples, il arrive souvent aussi que les dialectalismes et les emprunts s'y interfèrent.

Le $4^{\text {ème }}$ niveau est donc l'emprunt lexical. Cinq langues, dans nos gloses botaniques, sont en rapport d'emprunt avec l'arabe. Ce sont le latin, le berbère, le persan, le grec et le syriaque, qui donnent, ensemble, 39 termes d'emprunt. Le « latin », ou plutôt le «latin espagnol», est la plus importante de ces langues. Elle a donné aux glossateurs 24 termes qui sont souvent étiquetés par «latinni », et parfois par «latiniyya $»$ ou $《$ a jamiyya $\|^{57}$. La place des quatre autres langues est nettement inférieure. La deuxième, le berbère, n'est représentée que par six emprunts ${ }^{58}$, dont trois ne sont pas étiquetés : thāqqā, thāqua et arghīs. La troisième, le persan, est l'origine de quatre termes ${ }^{59}$. Puis il y a deux termes empruntés au $\operatorname{grec}^{60}$, et un seul terme emprunté au syriaque ${ }^{61}$.

On constate donc que, parmi les quatre niveaux de langue représentés dans les gloses, le plus important est le dernier: l'emprunt lexical. Cependant, ce phénomène d'emprunt s'inscrit bien dans une tradition assez connue depuis le $\mathrm{III} / \mathrm{IX}{ }^{\mathrm{e} m e} \mathrm{~s}$., avec les traducteurs des ouvrages de médicaments simples eux-mêmes. Pour faire face aux cases terminologiques vides, ils faisaient souvent recours à l'emprunt lexical, en utilisant des équivalents appartenant aux langues utilisées sur la terre de l'Islam, en Orient, et particulièrement les termes per-

L'appartenance dialectale des termes égyptiens est désignée dans la glose. Quant aux deux autres, leur appartenance est désignée dans le Tafsìr d'Ibn al-Bayțār.

${ }^{57} \mathrm{Ce}$ sont lïlyūn et lilya (§ 1), ishbațäla (§ 2), yadhra bädhira (§ 3), yunja (§ 4), ishbïka (§ 5), yarba mūrqa (§ 7), qāsham (§ 8), jannamū (§ 9), balshamū et yarba lubbayra (§11), äla (§12), sibinya (§15), luqsh (§18), arbāqa da lawra (§19), zanbüquh muntūshuh (§22), shitji et sanlutji (§23), astab et rujäl (§26), ishkịtshiyuh (§27), jāla (§ 29), qarnulya (§ 34), mațūnīs (§ 37) et abillāna mawrā (§ 40).

${ }^{58}$ Ce sont asmìman (§ 7), thāqqā et thāqā (§ 17), bashkābardīn et arghīs (§ 27), et jawdhar (§35).

${ }^{59}$ Ce sont dahmast et rand (§ 19), zirishka (§ 22), et azädarakht (§ 44). Il y a deux autres termes que nous n'avons pas voulu mentionner parce qu'ils existent déjà dans la MMA : rāsan (§ 12) et banjankusht (§ 28).

${ }^{60}$ Ashbaltiyūn (§ 2) et kabarrīs (§ 17).

${ }^{61}$ C'est ìlāqdìshā (§28). 
sans et syriaques qu'ils connaissaient bien. Ce recours aux emprunts, en utilisant les "langues islamiques", a été massif dans les commentaires - ainsi que dans les révisions - des Andalous portant sur les termes grecs de la $M M A$. Mais au lieu du persan qui avait un statut particulier au Mashreq et surtout chez les traducteurs de Bayt al-Hikmah à Baghdād, nos commentateurs andalous préféraient, pour « arabiser» les termes grecs de Dioscorides, les deux « langues islamiques » locales : le latin, dans sa variété espagnole, et le berbère. La même approche, comme nous l'avons constaté, est suivie dans les gloses de notre ms de Paris.

\section{Les gloses ou les Hawāshī de la $1^{\text {ère }}$ maqäla}

Pour avoir une idée claire des gloses du ms, nous proposons une édition critique des gloses de la $1^{\text {ère }}$ maqāla. Nous avons choisi 44 gloses lisibles, que nous considérons comme de vrais articles ou de vraies entrées d'un dictionnaire bilingue, du même genre que le Tafsìr d'Ibn al-Bayțār par exemple. C'est pour cela que nous adoptons, en éditant ces gloses, la même méthode que nous avons suivie dans l'édition du Tafsìr d'Ibn al-Bayțār. Chaque article est donc suivi de deux genres de notes, de grandeur différente. Les premières sont relatives à l'entrée elle-même : on y donne une documentation détaillée sur l'article dans les trois versions de la $M M A(K H, T$ et $W$ ) et dans deux de ses commentaires : le Tafsìr d'Ibn al-Bayțār et le Sharh anonyme. Les autres notes sont relatives au texte: on y commente, surtout, la lecture des termes et les étymologies des emprunts lexicaux.

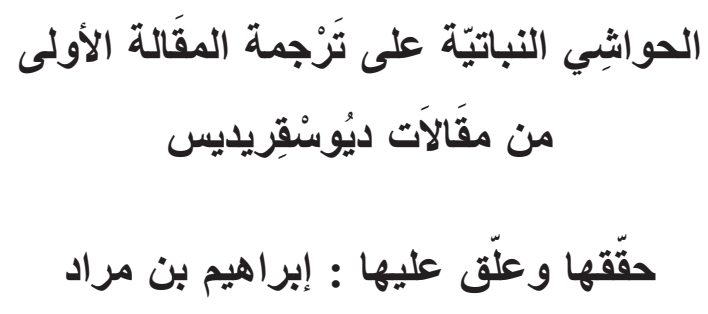

Al-Qanțara (AQ) XXX 2, julio-diciembre 2009, pp. 581-622 ISSN 0211-3589 


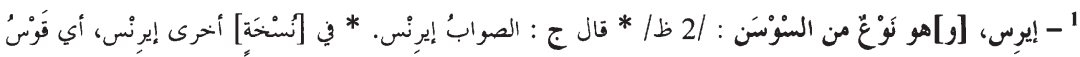

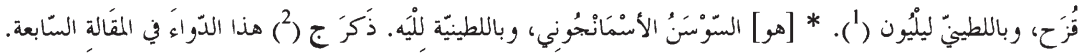

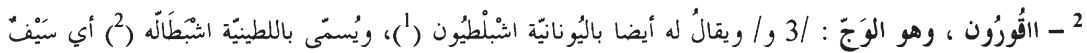

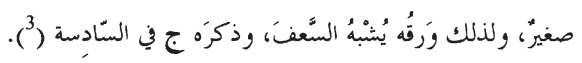

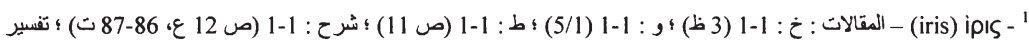

: 1-1 (ص 111). وفي النص كما يلاحَّ ثلاث حواش : الأولى حول رسم الاسم، نقلا عن (ج) ، أي ابن جلجل؛ والثانية والثالثة تقسيريتان. وتنلّ النجمة (*) في النصوص المحقةة على بداية حاشية جديدة. كما أنَ بعض الإحالات قد تقرن بعض الحروف، منها الرموز الثلاثة المرجعة إلى "المقالات" ، وهي : (خ) = مخطوطة باريس (KH) التي اسئخرجت منها الحواشي؛ (و) = نص المقالات اليوناني (W) الذي نشره ولمان (Wellmann) ؛ (ط) = نصها العربي المطبوع (T). ومنها في التعاليق: (ع) = "النص العربي"؛ (ت) = "النص المترجم"؛ (ب) = نص ط. بولاق من كتاب الجامع لابن البيطار ؛ (ف) = فقرة. (1) هو و "لليه" الذي سيرد من اللاتينية Lilium - ينظر : (2) هذا الحرت يُرجع إلى جالينوس؛ ولم يذكر جالينوس هذا الدواء في كتابه الادوية المفردة. وقد ورد في التفسير مثل ما ورد هنا : أن جالينوس ذكر هذا النبات في المقالة السابعة، لكن ابن البيطار قد استدرك في كتاب الجامع (71/1 ب، 177/1 ت، ف 216) فقال "ولم يذكره الفاضل جالينوس في بسانطه البتَّ"، و"البسانط" جمع "بسيط"، وهو الدواء المفرد. 88-87 (akoron) ầkopov - ${ }^{2}$

$$
\text { ت) ؛ تقسير : 1-2 (ص 111). والحاشية منقولة عن ابن جلجل، ونمها منسوب إليه في الشرح. }
$$
(1) نكره أبو الخير (عدة الطبيب، ص 27 ع، ف 355) وذكرَ في الشرح ورسم فيهما "اشبطليون" بباء فطاء فلام ، والمصطلح

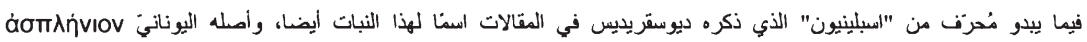
(asplênion) (2) خصه أبو الخير بمادة مستقلة (عمدة الطبيب، ص 27ع، ف 355) وأوتَعه على نباتين هما "نوع من الشعير" و"الأقارون وهو الوج"، وذكِر في الشرح، وتفسيرُ صاحب الحاشية له هنا بـ"سيفت صغير" لا يدع مجالا للشكك في أنه من اللاتينية الاسبانية espadilla

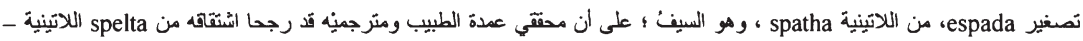
تتظر ترجمة عمدة الطبيب، ص 37 (تع 7) - ينظر أيضا Glosario, 193-194 ; GVR, 114, § 221 ؛ وينظر ايضا RGBA, 137-138 .Claudii Galeni Opera Omnia, C.G. Kuhn (éd.), I-XX, Leipzig, 1821-1833, XI, 819 (= GAL), ينظر (3) Al-Qanțara (AQ) XXX 2, julio-diciembre 2009, pp. 581-622 ISSN 0211-3589 


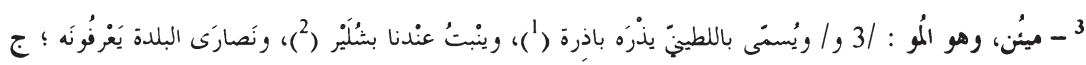

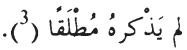

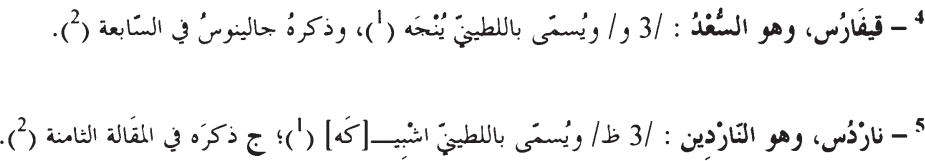

( mêon Mñov - 3 89-88 ت) ؛ تتسير : 3-1 (ص 112) ، وجل النص وارد في الشرح عن ابن جلجل، وكنلك في عددة الطبيب لابي الخير (ص 349 ع، ن

(1) كذا في الأصل، و المصطلح الذي ذكره ابن جلجل حسب الثرح هو "ينره" ، وقد ذكر له ابو الخير في عددة الطبيب (ص

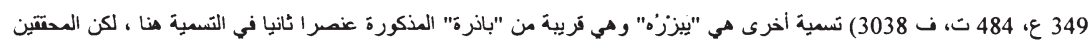

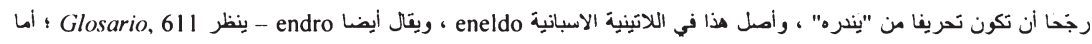

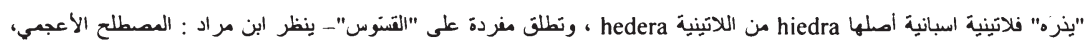
$R G B A, 210 ؛ 2006$ (ن) 818/2 (2) في نص ابن جلجل وابي الخير "بجبل شلير ".

(3) في التقسير "وذكره جالينوس في المقالة السابعة" ، وقد ذكره جالينوس بالفعل في المقالة السابعة ـ ينظر :GAL, XII, 78. (kuperos) Kümعpos - ${ }^{4}$ تقسير : 1, (ص 112) (112). (1) ذكره ابن جلجل حسب الشر ح، وخصه ابو الخير (عدة الطبيب، ص 581 ع، 767 ت، ف (5081) بفترة مستخلة ورسمه فيها

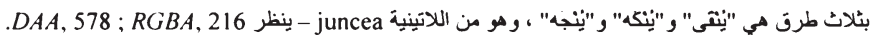
.GAL, XII, 54 ينظر (2) (nardos) vápסos - 5 (ص 13 ع، 91 ت) ؛ تنسير : 1-6 (ص 113). وتد ذكرتت أنواع الناردين التي تحتث عنها ديوسقريديس تحت هذه المادة في (خ) و(ط).

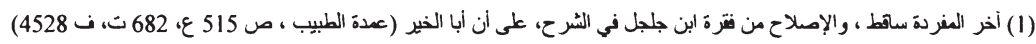

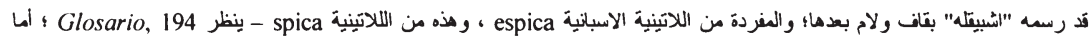

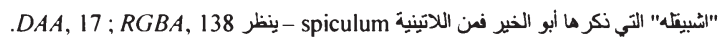
.GAL, XII, 84-85 ينظر (2) Al-Qanțara (AQ) XXX 2, julio-diciembre 2009, pp. 581-622 ISSN 0211-3589 


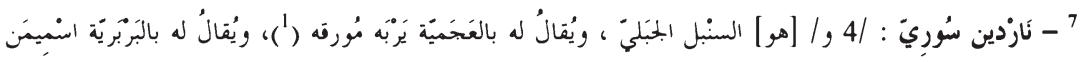

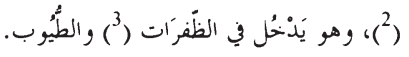

8 ه قَستيًا، وهو الستليخَةُ : /5 و/ ويُقالْ له باللطينية قَاشم (')، ج س.

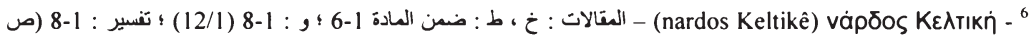

113) ؛ ولم يُخصن في الشر ح بمادة مستمَة.

(nardos Suriakê) vápठ̄os Eupıaki் - '

التعليق على المادة (5))، ولم يُخصن في الشر ح والتفسير بمادة مستَّلة أيضا، والحاشية التي وردت في (خ) وسجلناها تد ذكرت تعقيبا على قول ديوسقريديس - في الحديث عن "ناردس قليطيتي" الذي سبت ذكره - "وقوته مثل قوَة الناردين السوري" ؛ والملاحظ أن ديوسقريديس قال عن الناردين السوري : "يقال له السوري لا لانه يوجد بسوريا لكن لان الجبل الذي هو فيه يُوجد منه منا يلي سوريا". (1) في الأصل "صورتة" بالصاد، وتد ذكر المصطلح تامًا ابو الخير الإشبيلي في عمدة الطبيب، ص 583ع (ف 5113) وتال إنه "الرزو" : وذكر "مورتا" وحدها في مادتين مستَلتين عرفها في أولاهل (ص 331 ع، ف 2969) ب"الطرفاء"، وهذه من اليونانية

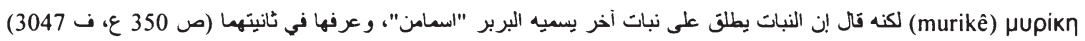
بـ"اسمامن"؛ وذكر "مورقًا" ابن البيطار في كتاب الجامع (106/4 ب، 345/3 ت (ف 2188) - والممطلح بعد هذا مركب من "يربه"

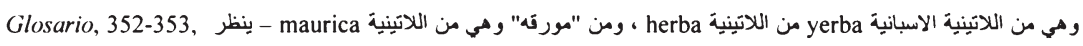
612 ؛ الصصطلح الأعجمي، 769/2 (ت 1888) ؛ DAA, $515 ;$; RGBA, 212. (2) من البربرية asmamen - ينظر المصطلح الأعجمي، 769/2 (التعليق 105).

(3) في الأصل "الضفرات" بالضساد، والمعروف في الاستعمال "أظفار " و"ظافير"، جمع "ظثر"، وهو "ضربّ من الطيب أسود متكلُ من أمله على شكل ظفر الإنسان يستعمل في البخور" - ينظر ابن منظور : لسان العرب، نشرة يوسف خياط دار لسان العرب، بيروت، 1970، 645/2 (ظفر)؛ وقد ذكر الغافقي أيضا - فيما نقله عنه ابن البيطار - أن هذا النبات "يستعطل في لخالخ الطيب". (kassias) kadoias - ${ }^{8}$ 15ع، 97-96 ت)؛ تفسير : 13 (ص 115) ؛ ونصن الحاشية مطابتّ لما وردّ في الشُرح. Al-Qanțara (AQ) XXX 2, julio-diciembre 2009, pp. 581-622 ISSN 0211-3589 


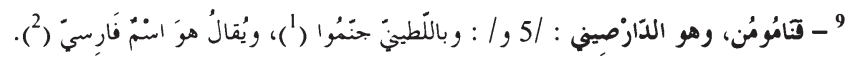

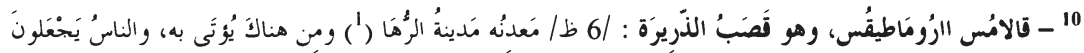

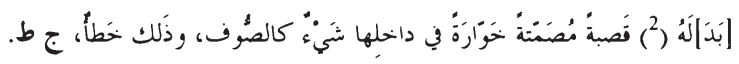

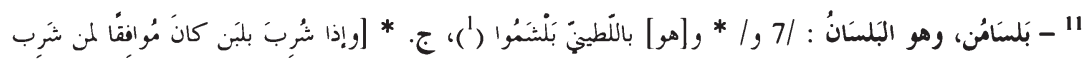

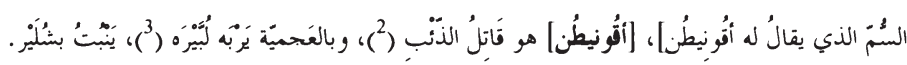

(1) كذا ورد الاسم بالشين في عمدة الطبيب ايضا ( ص 518ع ، 687 ت، ف 4546) ، ورسم بالسين "قاسم" في الشرح ، وقد ارجع في الر اجع التي بين أيدينا إلى الاسم اللاتيني لهذا النبات وهو cassia او casia دون تفسير لوجود الميم في أخره - ينظر

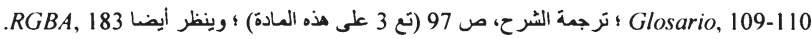

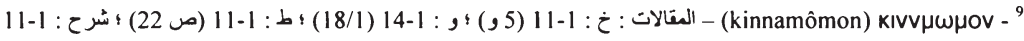

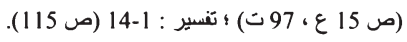

(1) الاسم مذكور في الشر ح في نص منسوب إلى ابن جلجل ، وذكره مولف عمدة الطبيب ( ص 200 ع ، ف 1929)، وقد رسم في

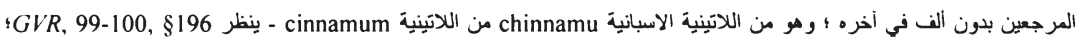
ترجمة الشرح ، ص 97 (تع 3) ؛ (2) الاسم الفارسي هو "دارضصيني" ، وأمله الفارسي "دازجيني" (dār-Čini) - ينظر المصطلح الأعجمي، 369-368/2 (ت

(1) في الأصل "الرمقا" ، والإصلاح من فترة ابن جلجل في الشرح ؛ وقد ذكر أبو الخير (عدة الطبيب، ص 479 ، ف 4230) إن

"نباته يكون بالمسين والأهواز وبالبصرة وبنيل ممر".

$$
\text { (2) الإصلاح من نص الشرنح أيضا. }
$$

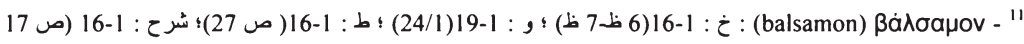

ع، 102 ت) ؛ ولم ترد المادة في التنسير. وفى المادة حاشيتان كس يُلاحظ ، الأولى على المصطلح اليونانى الأصلي، وهي منقولة من ákóvitov (تفسير ابن جلجل حسب الشّر ح ، وكما تَل على ذلك نسبتها إلى (ج)؛ والثانية على مصطلح ورد داخل النص هو "فونيطن (akoniton) خانتُ النبر وغيره من الحيوان، يُعرفت عندا بالنبال ، ينبت بناحية إلبيرة"، و هي أيضا منتولة من ابن جلجل حسب ما ورد في الشُرح : 


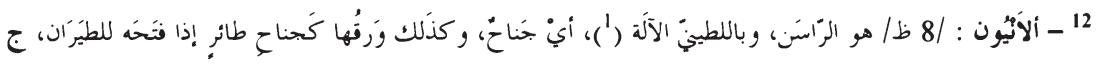

$$
\text { ط س و. }
$$

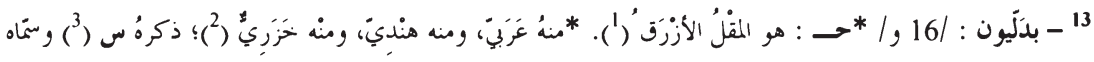

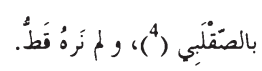

(1) ذكر في الشرح عن ابن جلجل ورسم بالسين "بلسموا" ، وذكره ابو الخير (عدة الطبيب، ص 74 ع، ف 724) ورسمه بشين

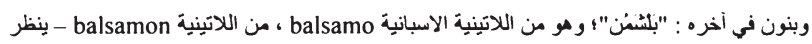
.Glosario, $30 ; G V R, 28, \S 60 ; R G B A, 113$

(2) هذا اسم أحد نو عين من هذا النبات ذكر هما ديوستريدِيس في المقالة الرابعة ، ويستى "خانق الذنب" ايضا ، وأما النوع الأخر

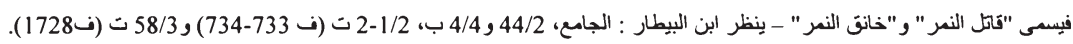
(3) لم نعتر عليه في مراجعنا ، وهو متكون من "يرَبه" و هي من اللاتينية herba ومعناها "عشب، نبتَّ" ، ومن "لتيره" و هذه من

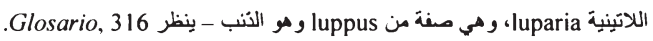
(Helenion) Edغ̇ंviov - 12 18 ع، 108-109 ت) ؛ تنسير ، 1-27 (ص 119 1 ) ؛ ونص الحاشية موجوذ في الشر ع، نتلا عن ابن جلجل.

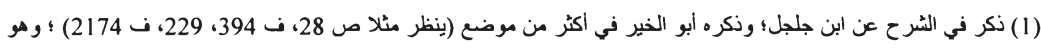

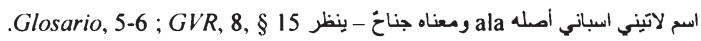

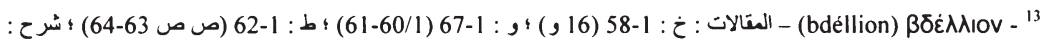

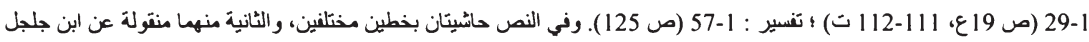
حسب ما نكر له في الشرح، مع بعض اختلاف، و عبارة "ولم نره تط" عبارئه.

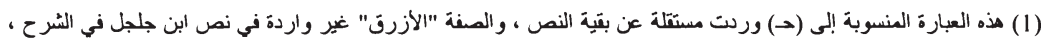
وهي واردة في تفسير ابن البيطار حيث نجد "هو المقل الأزرق بانواعه". (2) في الأصل "خوزي" - نسبة إلى "خوزستان" ببلاد فارس ، والإصلاح من نص ابن جلجل في الشُرح ، وصَ نسبه إلى "بلاد

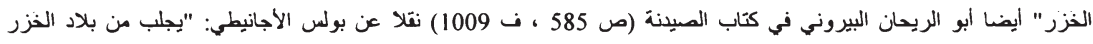

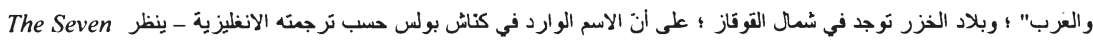
- Books of Paulus Aeginita, F. Adams (transl.), London, 1854-1857, 3, 70

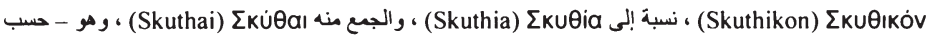
Al-Qanțara (AQ) XXX 2, julio-diciembre 2009, pp. 581-622 ISSN 0211-3589 


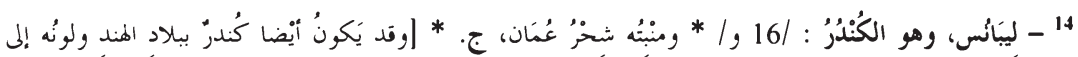

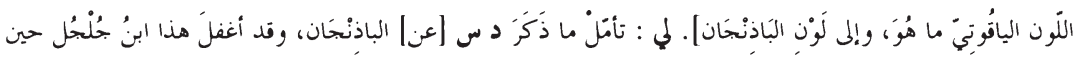

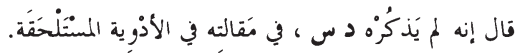

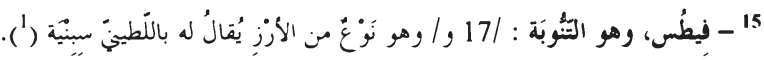

- A. Bailly, Dictionnaire Grec-Français, Paris, 1963, 1766 وشمل أسيا" ، وسنرى في التعليق (4) ان الاسم نفسه تد ترجم في كتاب الأدوية المغردة لجالينوس بـ"الصقالبة".

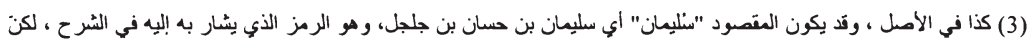
الذي نسبه إلى الصقالبة كما سيرد هو جالينوس. (4) في الأمل "الصتلي" ، وهذه النسبة هي الشانعة في كتب الأبوية المفردة العربية ، وهي مذكورة في نص لجالينوس- ينظر مثّلا البيرونى في المرجع السابق ، ص 585 ؛ ابن البيطار : الجامع، 162/4 ب، و332/3 ت (ت 2157) ت، وقد نته لكلرك في ترجمة

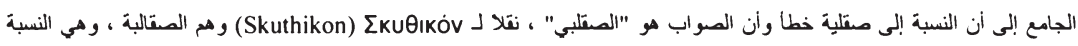

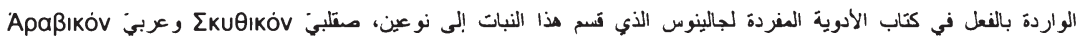
- (Arabikon) بلاد الصقالبة في ترجمة النص المنسوب إلى جالينوس، لان الاسم اليوناني المترجم واحد. (libanos) Aißavos - 14

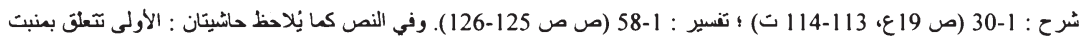

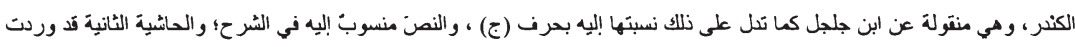

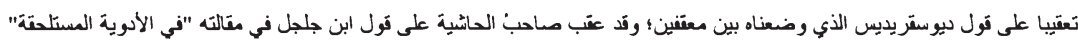

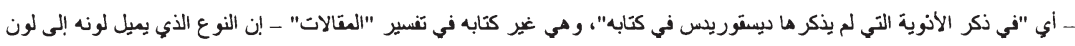
الباذنجان لم يذكره ديوستريديس في مقالاته. والاسم اليونانى لهذا النوع من الكنر هو "سيغرس" حسب (خ) و"سغرس" حسب (ط) ، وهو Xóvópos حسب (و). ونلاحظ أن "كندر" الذي ثُرجم به المصطلخ اليوناني هو نفنه من اليونانية (Suagrios) EuáyploS (khondros)

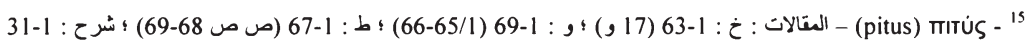

$$
\text { (ص 19ع، 119-115 ت) ؛ تنسير : 1152 (ص 126). }
$$

Al-Qanțara (AQ) XXX 2, julio-diciembre 2009, pp. 581-622 ISSN 0211-3589 


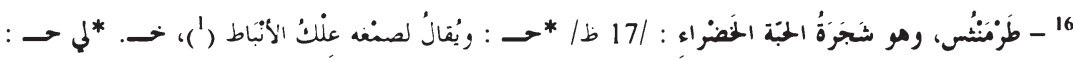

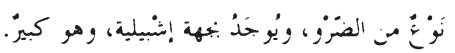

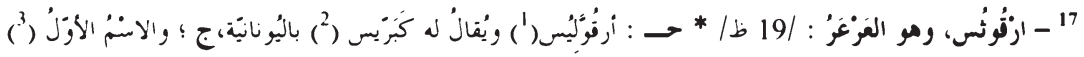

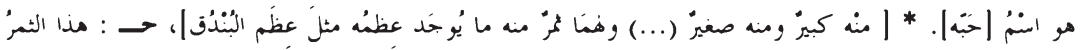

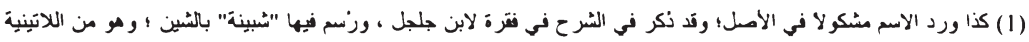
Glosario, 572 ; DAA. 273 - sabina

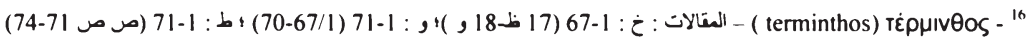

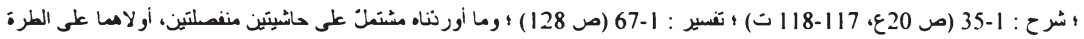

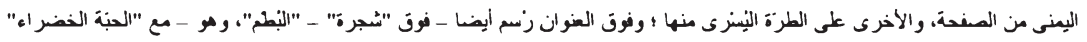

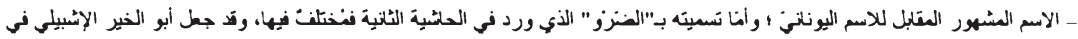

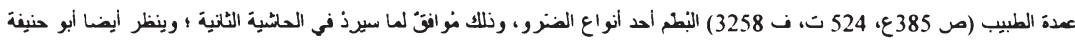
السينوري : كتاب النبات ، القاموس النبتى : القسم الأول، ا - ز، تحقين برنار لوين Bernhard Lewin، أبسالا، 1953، ص47 (ت 74 :

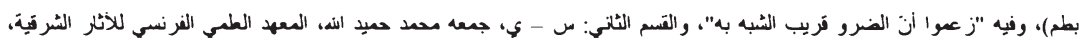

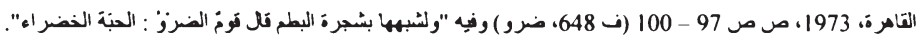
(1) هو الذي أنسار إليه ديوسقر يديس فى هذه المادة نفهها بقوله "والرطينى الذي من هذه الشجرة هو صمغتها، يوتى به من موضع

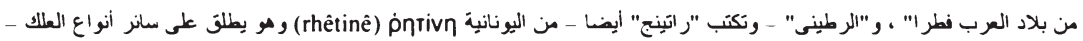
ينظر المصطلح الاعجمى، 398/2 (ن 930) ؛ على أن من مولفى الأدوية المفردة التدامى من بعتبر علك الأباط هو بذاته صسع الحبة الخضر اء أر البطع ، و هو راي ابن البيطلار في كتاب التضسير ، ومنه من يرى فيه "علك شجرة الفستق" وهو رأي إبحاق بن عمران حسب ما نتله عه ابن البيطلار في كتاب الجامع ، 133/3 ب، 465/2 ت (ف 1581) وراي ابن الجزار حسب ما نسبه إلبه ابن البيطلار فى كتاب التفسير (1 - 134 ، ص 154) ، و مو رأي أبي الخير الإتببلِ أيضا ، ينظر : عدة الطبِب ، ص 411 ع، 554 ت (ف 3479) ، وتد انتّد ابن جلجل بقوله : " وتول ابن جلجل على ان [علك الانباط] البطم وحده شعوذة و شنزّ لانه لم يأت على نلك بحجة كاطعة ولا بكلام تمِاسى متنع" - وتنظر فيما يلى مادة "فسطحيا" (ف 38). 17 1-42 (ص 22ع، 125 ت ) : تفسير : 15-7 (ص 130). و على الماذة حاشيتان : الأولى على المصطلح اليونانى، و هى منقولة عن ابن جلجل حسب الشر ح وحسب نسبتها إلِيه بحرف (ج)؛ و الثانية على تول ديوستر يديس الذي وضعناه بين معتفين. 


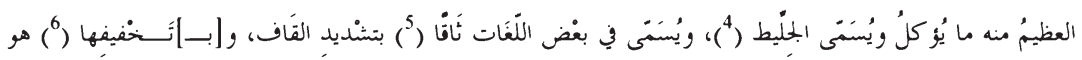

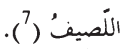

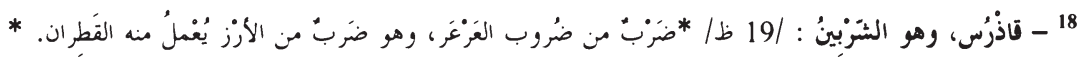

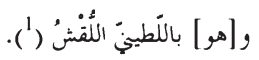

(1) كذا رُسبع الممطلح في الحائية، ظنا من ماحبها انه يُملح الرسع الأمليَ الوارذ في المتن.

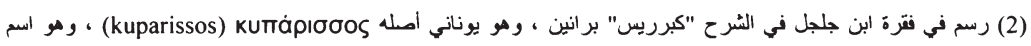

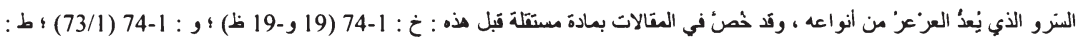

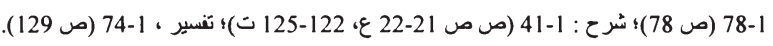

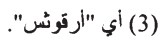

(4) خمنه ابو الخير في عمدة الطبيب (ص 125 ع، 195 ت ، ن 1366) بمادة مستقلة وعرته بانه "نوع من الابهل" ، وعنه أخذنا

(5) نكر الاسم أبو الخير (عمدة الطبيب، ص 404 ع ، 546 ت ، ف 3463 : عرعر) بالتشديد أيضا لكنه رسمه بالتاء المثناة

$$
\text { عوض الثاء وقال إنه بربري. }
$$

(6) أي "ثأا" دون تشديد للقاف، وتد خصه أبو الخير بمادة مستثلة في عمدة الطبيب (ص 104 ع، 166 ت، ف 1099) ، وهو اسم

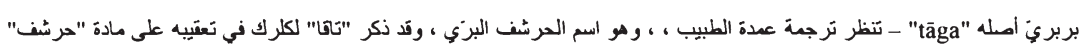
في ترجة كتاب الجامع لابن البيطار (432/1 ت، ف 658) وقال إنه اسم بربري يحمله الحرشف في الجزانر. (7) رسم في الاصل "اللصيت" بالقاف في أخره، والإصلاح من عمدة الطبيب ، ص 305 ع، 432 ت (ف 2722) ؛ وقد ذكر ابن البيطار هذا الاسم في كتابيه التفسير (3-14 ، ص 215) والجامع (18/2 ب ، 431/1 ت ، ف 658) ورسمه "اللصف" بدون ياء العذ وقال إنه بالعامية الأندلسية وإن ماده مكسورة. 18 1-44 (ص 22ع، 126-127 ت) : تنفير : 17-1 (ص 130). وفي النص حاثيَّان، فان عبارة "وباللطينى اللقش" منفملة في الأصل عن الحاثية السابقة. (1) العبارة في الأصل "وباللطيني اللتش"، و"هو" من إضافتًا. وقد ذكر الاسم دوزي عن ابن العوام في فلاحته - ينظر الكلمة D Dozy, R., Supplément aux dictionnaires arabes, Leiden-Paris, 1967, 2, 544 ( = Supplément) من اللاتينية luxa - ينظر : DAA, 483. Al-Qanțara (AQ) XXX 2, julio-diciembre 2009, pp. 581-622 ISSN 0211-3589 


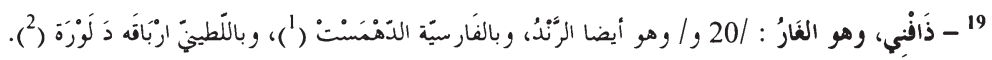

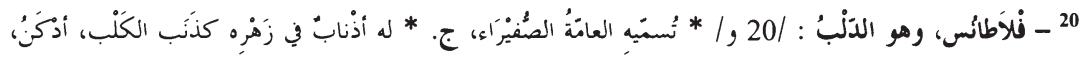

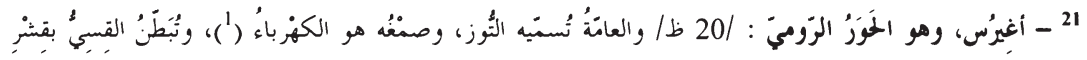

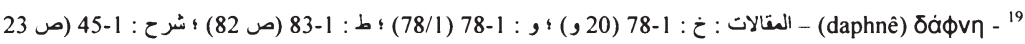

ع، 127-128 ت) ؛ تفسير : 1-78 (ص 130). ونص الحاشية منتول عن ابن جلجل، حسب ما ورد في الشّرح. (1) أمله بالفارسية "ذهمنت" (dahmast) - ينظر المصطلح الاعجمي ، 385/2 (ن 903).

(2) كذا ورد الاسم في الأصل، وورد في الثُرح "ارباتة ولور ه" ، باعتبار الو او حرف عطف ، أي هل اسمان مختلفان متر ادفان ،

وكذا ورد عذد ابن البيطار في التفسير : "وباللطيني أرباقه، وهو اللوره أيضا"، بينسا التسمية الواردة هنا ثكون مصطلحا واحدا مركبا بالإضافة باعتبار "د" أداة رابطة ، وقد وردت في كتب الادوية المفردة الاندلسية أسماء نباتِية كثيرة مشتملة على هذه الاداة التي تكتب فيها غالبا بالذال "ذ"، منها في كتاب عمدة الطبيب لابب الخير الإشبيلي "يربه ذموله" - ومعناه "عشبة البغلة " - و "يربة ذرننش" ومعناه "عشبة الادرة والفتوق" ، و"يربة ذفوقه" ومعناه "عشبة النار" (ص 581 ع، 766-768 ت، ف 5072، 5074، 5086), وهي ذات امل لاتيني اسباني هو "de" ، ولذلك فان أصل "ارباقه ذلوزة" فيما نرى هو "orbacco de lauro" ، والاصطل اللاتيني للمصطلح فيطا يبدو هو "orbacca lauri" ؛ على أن "أرباقه" الذي يكتب باللام "لورباته" أيضا - من اللاتينية laurabacca ، و "لوره" من اللاتينية Glosario, $316 ;$; GVR, 202, § 391 ينظر -laurus ، 20 شر ح : 1-47 (ص 23 ع، 129-130 ت) ؛ تفسير : 1-80 (ص 131). وفى النص حاشيَّان : الأولى هي المنسوبة إلى ج ، أي إلى ابن جلجل، وقوله مذكور في الشرح منسوبا إليه، والثانية هي المنسوبة إلى خ، ولم نعتر على هذه التحلية في مراجعنا. (aigeiros) aiykipos - 21 24 ع، 134-135 ت) ؛ تفسير : 84-1 (ص 133). ونص الحاشية منقول كله عن ابن جلجل الذي ذكر قوله في الشر ح وذكر في تفسير ابن البيطار مع تقديم في العبارة وتاخير، كما ذكره ابن البيطار في كتاب الجامع (42/2 ب، مع تحريف كثير، 473/1 ت، ف 725)، مع زيادات على ما ورد في الشُرح. 


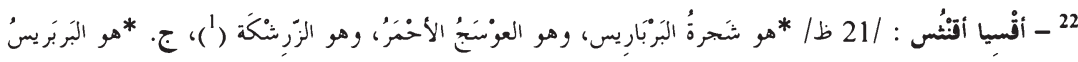

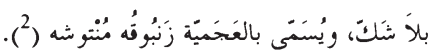

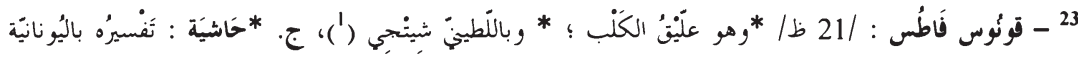

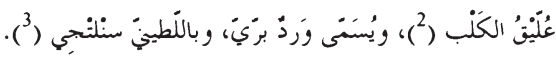

(1) كذا ورد في الثرح وفي التفسير أيضا ، لكن الراي في التفسير منسوب إلى ديوستريدِس ، ومذا مستخلص من قول مؤلف المقالات الذمس " ويقال أيضا إن الذي يسيل من صمغه في النهر الذي يسفى إيريدانوس [Heridanos = HoاdavoS ] يجمد في النهر

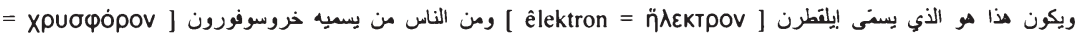
khrusophoron ] وهو الكهرباء" ، وتد انتُّد ابن البيطار في كتاب الجامع في مادتي "حور رومى" (42/2 ب ، 473/1 ت، نـ 725 ) و"كهرباء" (88/4 ب، 209/3 ت، ن 1982) مذهب النين يجعلون من صمغ الحور الرومي الكهرباء، وأرجعه إلى تثولّ التراجمة.

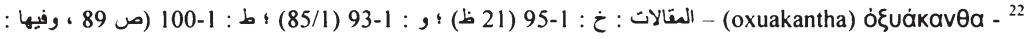

"أسو اتنطس وهو الأميرباريس") ؛ شرح : 1-62 (ص 26 ع، 145-146 ت) ؛ تنسير : 95-1 (ص ص 136-137). والنص مجموع من حاشيَّين : الأولى واردة على الطرة اليِرى من الصفحة ، وهي المنسوبة إلى ج، أي إلى ابن جلجل، لكن المنسوب إليه في الشر حهو

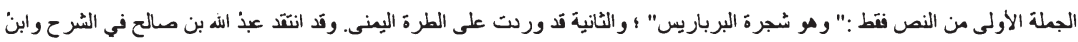

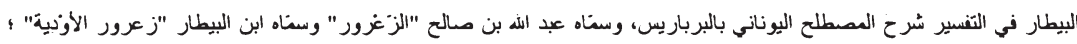

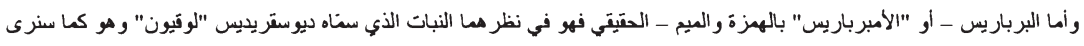

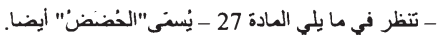

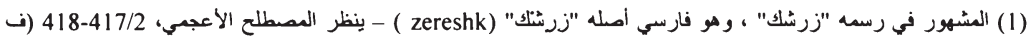

(2) ذكره ابو الخير في عددة الطبيب (ص 35 ع، 54 ت، ف 541) مقابلا لاميرباريس ورسه "زنبوقه منتوزه" - بالزاي عوض الشين في "منتوشُه" - وفسره بـ"عونسج جبلي" ، وهو اسم لآتيني اسباني مركب فيما يبدو من "montosus" و ـ ينظر

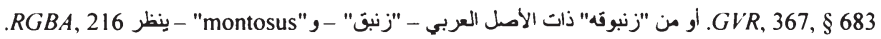
(kunosbatos) Kuvóoßatos - ${ }^{23}$ شرح : 1-63 (ص 26 ع، 146-147 ت) ؛ تنسير : 146-1 (ص 137). والنص المُبتُ منكرن من ثلاث حواش : الأولى هي الجملة الأولى

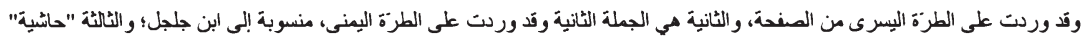
Al-Qanțara (AQ) XXX 2, julio-diciembre 2009, pp. 581-622 ISSN 0211-3589 


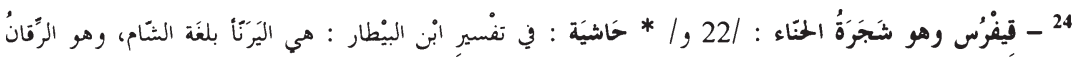

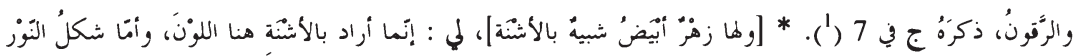

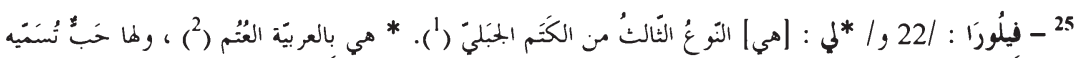

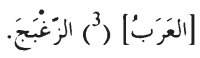

وردت في أسفل الصفحة. وتد رُبب العنصر الثانى من المصطلح اليوننى "فلطس" باللام عوض الالف في (خ)، وأصلح فوقه بـ"باطس"،

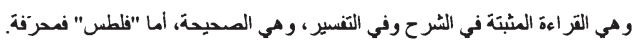
(1) كذا وردت في الأصل، ولها تراءات أخرى منها "سناتجي" التي سترد في هذه المادة؛ وينظر فيما يلي التعليق (3). (2) غليق الكلب ترجمة حرفية للممطلح اليوناني، وتد نبه إليها ابن البيطار في التقسير : "وتفسيره غيق الكلب، لان قانس

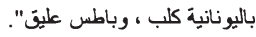

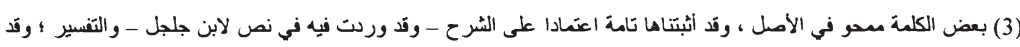

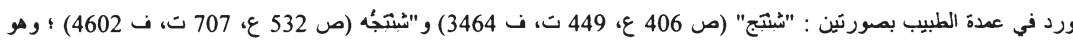

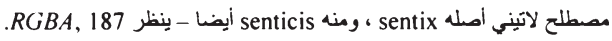
(kupros) kúmpos - ${ }^{24}$ (ص 27 ع، 148 ت) ؛ تنسير : 1-97 (ص ص 137-138) ؛ والنص المشبت متكون من حاشيَّن : الأولى "حاثيةّة منسوبة إلى كتاب التفسير لابن البيطار، وقد وردت فيه بالفعل، وهي فيه اتخ ؛ والحاشية الثانية في وصف النبات، قد وردت تعتيبا على قول نيوستريدِيس الموضوع بين معتقني. .GAL, XII, 54 ينظر (1) (philura) QıاAủpa - ${ }^{25}$

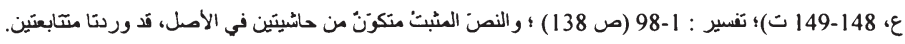

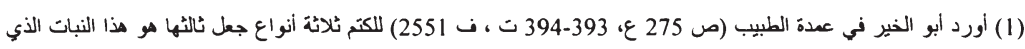
سنى في المقالات "فيلور ا" وسعاه أيضا "الز غبج" و "الزنبو ج" و "الغنثم".

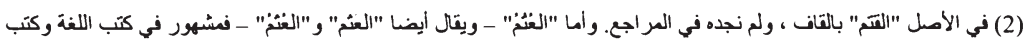

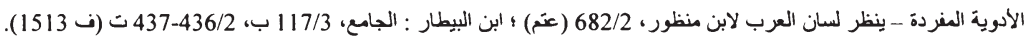
(3) الإضافة من نص ابن جلجل في الثرح. 


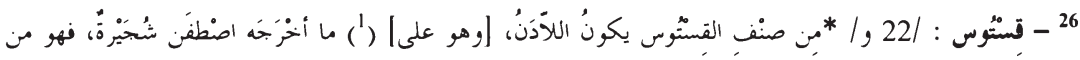

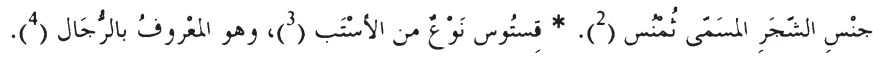

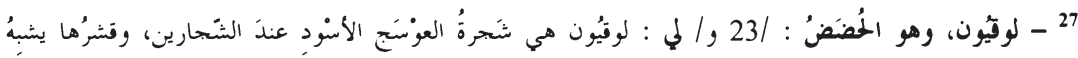

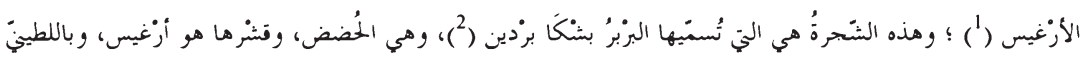

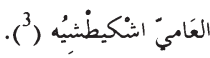

26 - (kisthos) KıбӨos - المقالات : خ : 98-1 (22,)؛ و : 97-1 (89-87/1 ؛ ط : 104 (ص ص 92-90)، وتد نكرت

تحت العنوان في (و) و(ط) ثلاثة انواع من هذا النبات منها المسنى بـ"اللان"، واما (خ) فت استّل فيها النوع الثالث - وهو "اللادن" عن النو عين الأول والثانى فُصن بمادة مستقلة؛ شر ح : 1-66 ( ص ص 27-27 ع، 149-154 ت) ؛ تفسير : 1-99 ( ص ص 138-139).

$$
\text { (1) إضافة بعضضيها تمام التركيب والمعنى. }
$$

(2) الثمنس - والثمنش بالشّين أيضا - هو حسب تعريف ابن البيطار له (الجامع ، 151/1 ب، 334/1 ت، ف 452) "اسم يوناني

لما كان من النبات بين الشجر والحشيش"، والمغردة من اليونانية 293/2 (thamnos) Oájuvos - ينظر المصطلح الأعجمي،

(3) خمه ابو الخير بمادة مستخلة في عدة الطبيب (ص 40-41 ع، 63-65 ت، ف 549)، وهو لاتيني اسباني أصله estepa

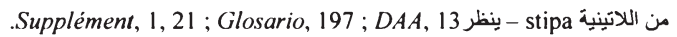
(4) كذا بالجيم في الأصل ، وقد نكر المصطلح ابو الخير في عمدة الطبيب ورسمه "رُشال" بالشين (ص 213 ع،315 ت ، ف 2080) ، والواحدة منه "رُشاحه" (ص 210 ع، 310 ت، ف 1999 ، وينظر فيه ايضا ص 41 ع، 64 ت، ف 549)، وتد ورد في

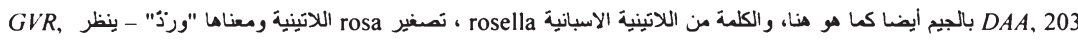
$.253, \S 488 ; D A A, 203 ; R G B A, 191$ (lukion) Aúkıv - 27

$$
\text { شرح : 1-69 (ص ص 31-29ع، 155-160 ت) ؛ تفسير : 102-1 (ص ص 140-141). }
$$

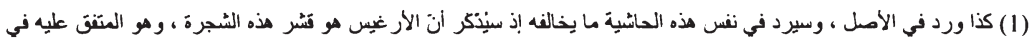

$$
\text { المصادر ـ و"أرغيس" بربريتة املها "a-arghis" - ينظر المصطلح الأعجى، 24-23/2 (ن 12). }
$$

(2) لم يخل المصطلح - وخاصة في عنمره الثاني - من الطمس في الأصل، وقد ذكره أبو الخير في عددة الطبيب ورسم فيه

بطرق مختلفة، منها "أشكذ" و "أشكذ برنين" (ص 35 ع، 54 ت، ف 541) و "اسكر بردين" (ص 417 ع، 561 ت ، ف 3507).

Al-Qanțara (AQ) XXX 2, julio-diciembre 2009, pp. 581-622 ISSN 0211-3589 


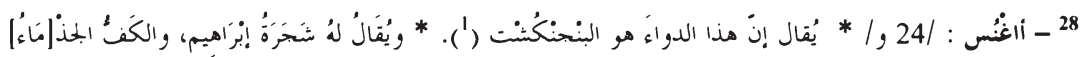

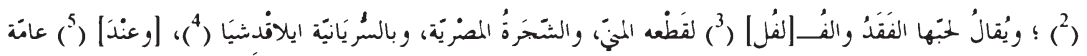

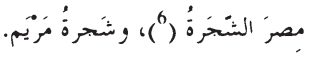

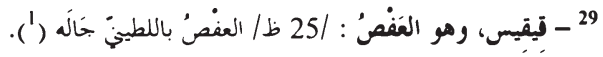

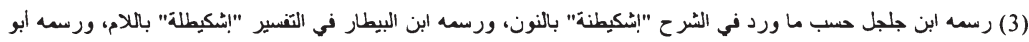

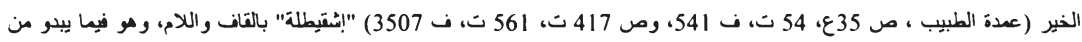

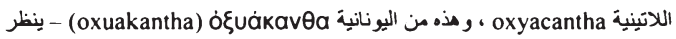
.Glosario, 196-197; DAA, 18, RGBA, 112 agnos) ầvos - 28 وهو البنجكست")؛ شرح : 12-1 (ص ص 32-31ع، 160-163 ت) : تفسير : 105-1 (ص ص 142-143). ويتكون النص المُبت من

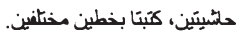
(1) هو مصطلح فارسي أصله "panj - angusht" - ينظر المصطلح الأعجمي، 233-232/2 (ف 541). (2) نمف الكلمة مسقط بعبب التصوير ، وقد ذكر "الكفت الجذماء" ابن البيطار في التفسير ، وذكر المصطلح في كتاب الجامع أيضا (74/4 ب، 184 ت، ف 1950) ورسمه "كن اجذم" و عده اسما مشتر كا يُطلق على ثلاثة نباتات مختلفة. (3) نمف الكلمة مسقط بعبب التصوير أيضا ، وتد ذكر المصطلح ابن البيطار في التفسير كنلك، وهو عنده "شجرة الفلفل عند عامة امل الأندلس ، وفلفل الصقالبة". (4) ذكره ابن البيطار في التفسير ورسه "إيلاتديشا" وتال إنه سريانى أيضا، وتد ذكره ابو الخير في عدة الطبيب لكنه حرنه ilānā qaddishā فرسه "إيلانه فريا" وعده من الإفرنجية (ص 457 ع، 609 ت، ف 3831) ، وهو مصطلح سرياني فغلا امله ومعناه شُرة مقنسة - ينظر ص 609 من ترجة عمدة الطبِب ، التعلين (8). (5) لم تظهر في الأصل بسبب التصوير. (6) كذا وردت في الأصل، وعند ابن البيطار في التفسير "وحبها هو حب الشجرة بديار مصر ". 77-1 المقالات : خ : (kêkis) knkis - 29 (ص 33ع، 167-168 ت) ؛ تفسير : 109-1 (ص ص 145-144). وقد نتل لكلرك في ترجمة الجامع (457/2 ، ف 1564) نص هذه

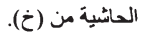
(1) ذكره ابن البيطار في التفسير ورسمه "جوله" ، ومو ممطلح لاتيني أمله Galla - ينظر Glosario, 241. 


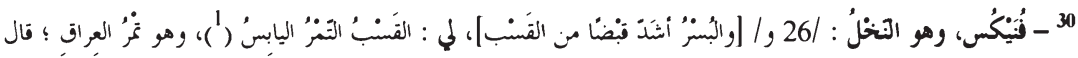

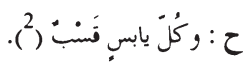

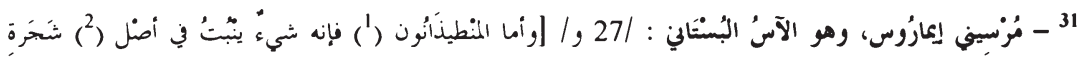

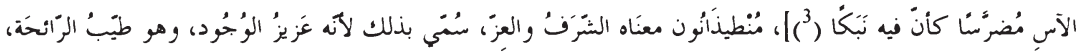

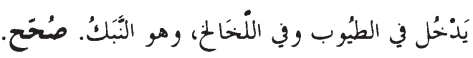

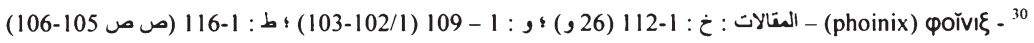
؛ شر : : 199 (ص 33ع، 169 ت) ؛ تفسير : 1-111 (ص 145) ؛ والحاشية على مصطلح "تسبّ" الذي استعط فى ترجمة الجملة التي وضعناها بين معقنين ؛ ويْلاحظ في ترجمنها اختيار" المترجمين - اصطنن وحنين - المصطلح المناسب من معجم البينة العربية التي يكثر فيها النخيل، ولم يترْجماه بمعناه اللغوي العامَ - ينظر التعليقان (1) و(2) التاليان على هذه المادة.

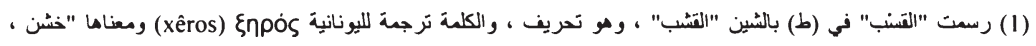

$$
\text { منب" ؛ و وينظر لسان العرب، 83/3 (تسب). }
$$

(2) القول هنا منسوب إلى (ح)، وهو أبو حنيفة الدينوري ، فنى الملتَّطات من كتاب النبات (ملتَطات ما نسب عند المتاخرين إلى

المجلد الأول و الثاني والر ابع الضانعة من كتاب النبات لاببي حنيفة أحمد بن داود بن ونتد الدينوري، جمعها محمد حميد النه، بيت الحكة،

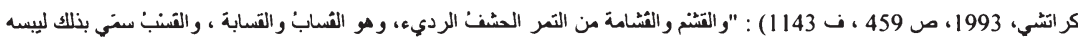
وتلة مقره ، وكل ملب شديد تسنب" ، "و المشتر" ما تحلب من التمر من غير ان يغصر ؛ وفي لسان العرب "القسب : الشديد اليابس من

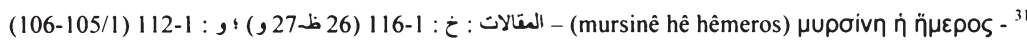

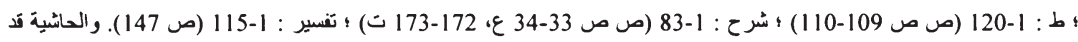
وردث في الأمل تعيبا على مصطلح "منطيذانون" الذي ورد في فترة داخل الماذة (ينظر خ : ص 27 و؛ و : 106/1؛ ط : ص 110)،

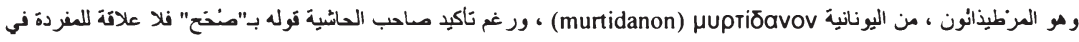
الدلالة بـ"الشّزت والعز" كما ثو هم، ولعله ذهب إلى ذلك اعتمادا على ترجمته العربية بـ"البنك" الذي بعنى أمل الشيء وخالصه - ينظر التعليق (3) على هذه المادة.

Al-Qanțara (AQ) XXX 2, julio-diciembre 2009, pp. 581-622 ISSN 0211-3589 


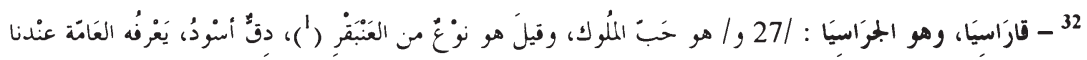
بالطرَنِين (2)، كَذا [في] ج.

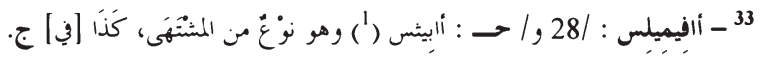

(1) في الاصل "المِطِيذانون" بالياء بعد الميِ، وأصلح فوقه بما ورد في الحاشِية، اي بايدال الياه نونا، وهو الرسم الذي ورد به

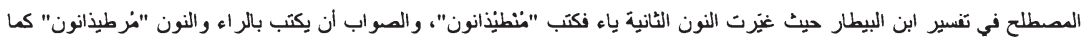
ورد في (ط) وفى المُرح. (2) كذا في الأصط، وفي (ط) "ساق". (3) كذا في الأصل بنون فباء منتوحتين، وكنا سيرد في نص الحاشِية، وصوابه "بنتكل" ، وهو - حسب نص المقالات هذا - زاندة

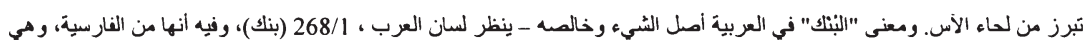

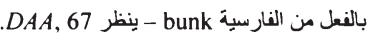
(kerasia) kepáola - ${ }^{32}$ (ص 34ع، 173-175 ت) ؛ تفسير : 116 (ص 148) ؛ والحاشية منقولة عن ابن جلجل حسب ما نسب إليه هنا وحسب ما ورد في

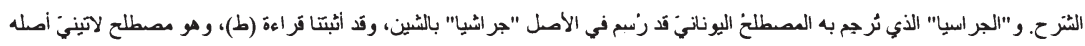
- cerasea (1) ويكتب "عبقر" دون نون أيضا، وهو منحوت من "عيون البقر"، وقد ذكره ابن جلجل، وذكره أبو الخير وذكر معه العبقر مر ادفين لعيون البقر (عدة الطبيب، ص 412ع، 556 ت، ف 3490). (2) في نص ابن جلجل في الشر ح "أنطريينة" بيانين ونون ، ولم نعثر على أمله الأعجمي في مر اجعنا ؛ على انت البرت ديتريش في ترجمته للشرح (ص 174، (تع (5)) قد ربطه باللاتينية الاسبانية "endrina". épimêlis) غ̇mınAis - ${ }^{33}$ - المقالات : خ : ضمن مادة "مسيفيلن"، وهو "الز عرور"، 125 (28 و) ؛ و : فيها أيضا ضمن مادة ابن جلجل "هو الفُتههى"، لكن عبد الله بن مالح الكتامي تال "لا أعرف هذه الشجرة" ؛ تفسير : 127 (ص 151) ، وقد قال ابن البيطار فيه عن النبات "لا علغ لي به" ، لكنه ذهب في كتاب الجامع (164/2 ب، 211/2 ت ، ف 1112) إلى أنه نو عُ ثان من الزّعرور ومال عنه "يُعرن هذا النوع عننا بالمشّهى". (1) كذا في الأكل ، اعتَادا من صاحب الحاشية أنه أملحع الرسم الذي ورد في امل المقالات للمصطلح ، وقد رُسبم في الشُرح "أبعلس" وهو رسم محيح. 


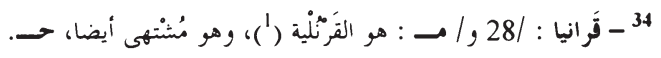

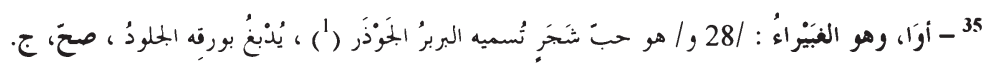

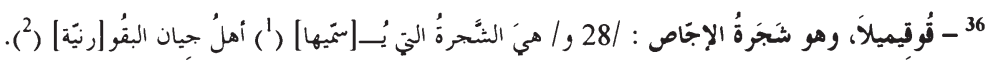

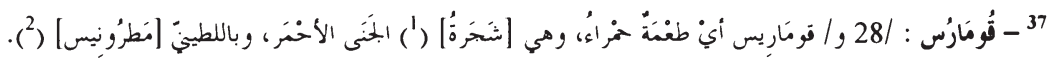

95-1 (krania) kpávıa - ${ }^{34}$ (ص 36 ع، 163 ت) ؛ تنسير : 128-1 (ص 152) ؛ وقد نقل لكلرك في الجامع (70/3 ت ، ف 1753) الجزء الأول من التعريف عن

(1) نكر في الشرح في تعريف الممطلح، عن ابن جلجل ورسم "ترنيليه" ، وخصه أبو الخير بمادة مستقلة في عمدة الطبيب (ص 499 ع، 661 ت ، ف1428) وجعله مقابلا لـ"تم انيا"، وذكره في مادة "ز عرور" (ص 233 ع، 341 ت، ف 2229) وقال "ونوع أخر من المشتهى تسميه العجم قرنلية" ، و هذا يويد ما ورد في هذه المادة من تعريف للممطلح بـ"المشتههى" إيضا ؛ وهو من اللاتينية الاسبانية cornella ، corniculum ، على ان المصطلح يُخلط بتسمية نبات أخر هو "إكليل الملك" الذي ورد في العقالة الرابعة -

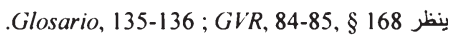
(oûa) oûa - ${ }^{35}$ ع ، 183 - 184 ث) ؛ تفسير : 129 (ص 152) ؛ ونص الحاشية منقول عن ابن جلجل كما ورد في الشرح ؛ وقد نتل لكلرك في الجامع ( 388/1 ت، ف 539) في تعليقه على مادة "جونر" التسم الأول من نص الحاشية من (خ). (1) من البربرية jawdaree او - ajdar - ينظر المصطلح الأعجمي، 323-322/2 (ن 754).

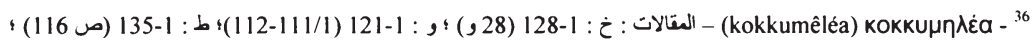
شر ح : 97-1 (ص 36 ع، 185-184 ت) ؛ تتسير : 130-1 (ص ص 152-153)؛ وثد نكر لكلرك في الجامع (12/1ت ، ف 21) بعض هذه الحائية منقو لا من (خ). (1) المضاف مستط في الأصل بسبب التصوير. (2) المضاف مسقط في الأصل بعبب التصوير ، وتد اتصا الفغردة من تعليق لكلرك على مادة "إجاص" في ترجمة الجامع.وقد رسمها bigournia بالرن اللاتيني، ويبدو أنها من اللاتينية الاسبانية bigornia، من اللاتينية bicornus ، وأصل معناها "سندان نو راسين" -- ينظر Glosario, 49-50 ; RGBA, 59

Al-Qanțara (AQ) XXX 2, julio-diciembre 2009, pp. 581-622 ISSN 0211-3589 


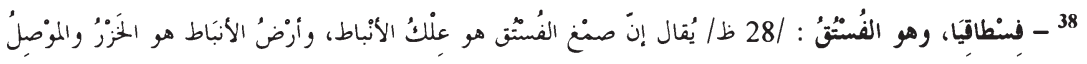

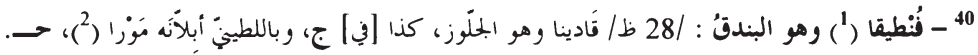

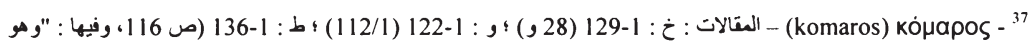

قاتل ابيه") ؛ شر ح : 198 (ص 37 ع، 185-187 ت) ؛ تنسير : 131-1 (ص 153) ؛ وقد نقل لكلرك في الجامع (92/3 ت ، ف 1807 : قطلب) بعض هذه الحاشية من (خ) ؛ وما في الحاشية مذكرر في الشر ح منسوبا إلى ابن جلجل، وفى التفسير ، وفيهما أيضا أن النبات بيسى "التطلب" و "قَّل أبيه".

(1) ساقطة في الأصل بسبب التصوير ، والإضافة من نص ابن جلجل في الشرح ح.

(2) ساحطة في الأصل بسبب التصوير، وتد أضفناها من الشرح - وفِه "مطرونيا" -. ومن التضسير - وهي فيه "باللطيني العامي

مطرونيةّ" - ومن تعلين لكلرك على ترجمة الجامع (وفيه "مطرونيس" الذي اثتبتا) ؛ والمطلح من اللاتينية الاسبانية matroño ، وهذه من أمل لاتيني مرجتح هو arbutrus من بإحدات إبدال وقلب مكانى في المغردة - ينظر .Glosario, $349 ; G V R, 174-175, \S 340 ; D A A, 505 ; R G B A, 159$

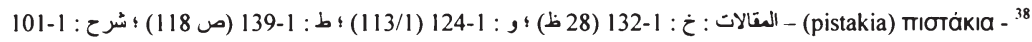
(ص 37 ع، 188 ت) ؛ تفسير : 1-134 (ص 154) ؛ والقسم الأول من الحاشية مذكور في التفسير منسوبا إلى ابن الجزار . وقد ذهب الدذب نفسه أبو الخير الإشبيلي في عمدة الطبيب ، ص 411 ع (ن 3479) وانتَّد ابن جلجل الذي رانى في فسحميا "صمغ البطم"، اي "الحبة الخضر اء"، على أنتار ائنا من قبل في مادة "طرمنس " (ن 16) انَ هذه الثجرة هي التي تسفى "علك الأنباط". (1) كذا عرت صاحب الحاشية "الأنباط" ، والمواب أن الاسع يطلق على جماعتين من الناس : إحداهما ظهرت في جزيرة العرب وتعرن بـ"أنباط الشام" والثانية ظهرت في بلاد ما بين النهرين وتعرف بـ"أنباط العراق" ، والجماعة الأولى عربية الاصل، الما بلاد الخزر فسكناهم في بلاد القوتاز - ينظر حول الأنباط : T.F. Graf-T. Fahd, " Nabat!", in EI², VII, 1993, 835-839

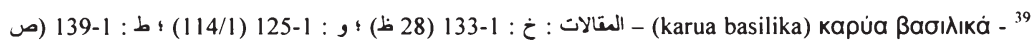
118 1) ؛ شرح : 102-1 (ص 37 ع، 188-189 ت ) ؛ تفسير : 135 (ص 154)، ونص الحاشية منقول عن ابن جلجل كما تدل عليه الإشارة إليه.

(1) (1) رسم في الشر ح رسما تريبا منه هو "قارياسيقا".

Al-Qanțara (AQ) XXX 2, julio-diciembre 2009, pp. 581-622 ISSN 0211-3589 


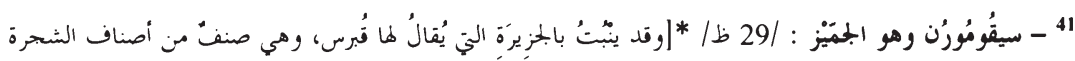

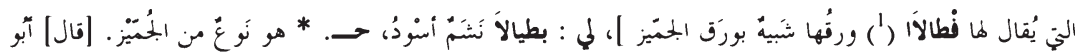

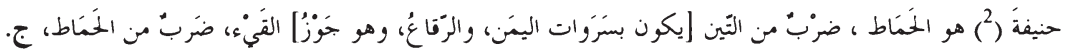

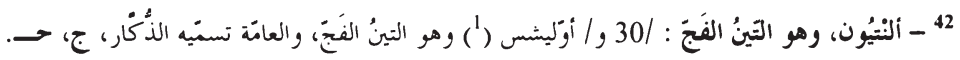

(karua Pontika) kapúa Povtıká - ${ }^{40}$

1-141 (ص 119) ؛ شرع : 1-103 (37 ع ، 189-190 ت) ؛ تتسبر : 1-136 (ص 154). ونص الحاشية منقول عن ابن جلجل. (1) في الأصل - (خ) - "قيطيتا" ، وتد أملح تحته بـ"تنطيقا" ثُم بـ"قادينا" الذي ورد في بداية الحاشية ؛ أما (ط) فورد فيها "بنطيقيا" ، وصواب رسم "تاروا بنطيتا" أو "قارا انطيتا" بالفاء ، ويبدو انه الرسم الذي أريد في (خ). (2) المصطلح الذي نكره ابن جلجل كما ورد في الشر ح هو "أبلانة" ، وذكره ابو الخير في عمدة الطبيب (ص 27ع، 37 ت ، ف 359 ، ص 133 ع، 207 ت ، ف 1387) مر انفا للجلوز ورسه "أبلانت" ، و مذه من اللاتينية avellana

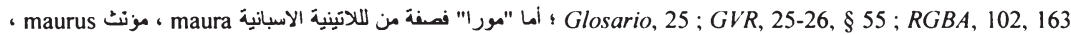
ومعناها "أسود" - ينظر Glosario, 353-354. - و 1 ط : 1-143 (ص ص 120-121، ص 121) ؛ شرح : 1- 106 (ص 37ع ، 192-191 ت، وفيه "بطيالا"، مادة منفملة عن "سيقومورن") ؛ تفسير : 138-1 (ص 155) ؛ وفي النص حاشيتان : الأولى نعرتن الدلالة الأصلية للمصطلح اليوناني، وهو بالفعل "النشم" الأنود" بالعربية، وقد سبَّ في هذه المقالة الأولى : pteléa) - المقالات : خ : 1-85 (20 ظ) ؛ و : 1-84 (80/1) ؛ ط : 1-90 (ص ص 85-84) ؛ شر ح : 1 - 52 (ص 25 ع، 135-136 ت) ؛ وأما الحاشية الثانية فنتولة من ابن جلجل ، وعنه اتمفا النقص والسقط

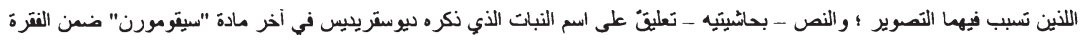
التي وضعناها بين معقنين، وهو "بطيالا" الذي يطلت حسب المقالات على نوع من الجميز ايضضا. (1) رسم في (خ) و(ط) بالقاف "تطالا" ، و هو تحريف ، وقد أصلح تحته في (ع) بـ"بطيالا".

(2) لم يرد تول ابي حنيفة في مادة واحدة في كتاب النبات بل إن ابن جلجل تد نتله من مادتي "تين" (النبات، 70/1 - 71 ، ف 125) و"حماط" (نفسه، 100/1 ، ف 219). 


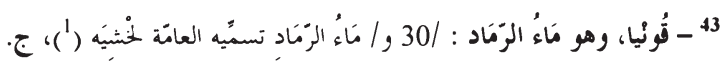

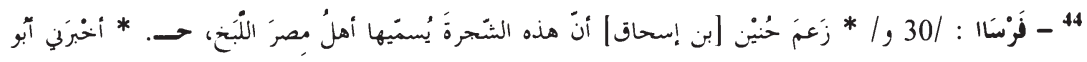

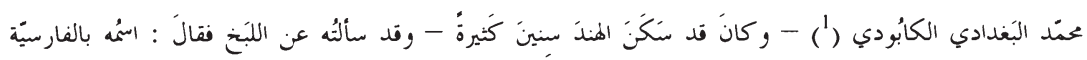

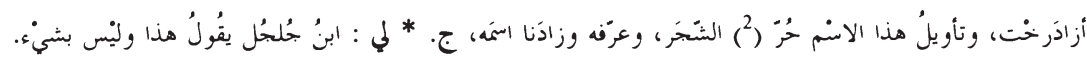

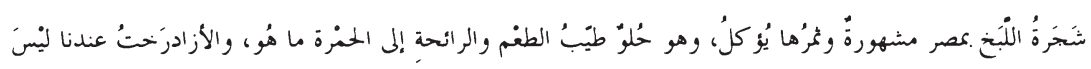

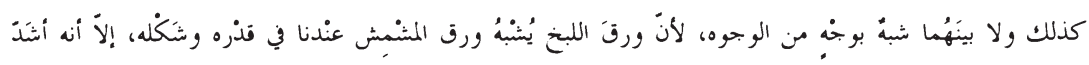

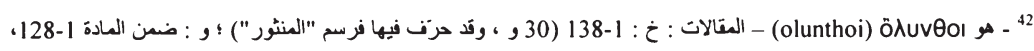

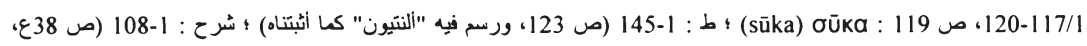

193 ت، وفيه ألنيون سيقون) ؛ تفسير : 1391 (ص 155، وفيه "المينون سيقيون"، وتد سبتت المادة فيه مادة "سيقا"، أي التين) ؛

ونصن الحاشية منتول من ابن جلجل.

(1 ) كذا رسم صاحب الحاشية المصطلح ظنا منه أنه يصلح ما ورد في الأمل.

(sukê konia) Gukn̂ kovia - ${ }^{43}$

146-1 (ص ص 123-124) ؛ شرح : 109-1 (38 ع، 193-194 ت)؛ تفسير : 141 (ص 156). والحاشية منقولة من ابن جلجل،

وقد ذكر بعضا منها لكلرك في ترجة الجامع، 236/3 ت (ت 2074) ؛ و"الزماد" العقصوذ في المدخل هو "رماذ التين"، وهي الترجمة

$$
\text { الحرفية للمصطلح اليوناني، وهي التي وردت في (ط) : "قونيا وهو رماد التين". }
$$

(1) كذا رسم في الشرع في فقرة ابن جلجل ؛ وهو من اللاتينية الاسبانية lexia من اللاتينية - lixivia ينظر

Supplément, 2, 538 ; Glosario, 305-306 ; DAA, 482

(persaia) חعpoaia - ${ }^{44}$

1-110 (ص 38 ع، 194-195 ت) ؛ تفسير : 142-1 (ص 156) ؛ والقول المنسوب في الحائشية إلى ابن جلجل مذكور في الشرح.

(1) كذا في الأصل، وفي نص ابن جلجل في الشّرح "الكافوري" بالفاء والر اء عوض الباء والدال ، ولم نعثر على ترجمة لعالم

حامل لأي من الاسمين.

(2) في الأمل "خرَّة"؛ و"أزادرخت" مصطلح فارسي أمله "آزاذ مرخت" (āzād derakht) - ينظر المصطلح الاعجمي،

DAA, $12 ؛$ (ن) $67 / 2$

Al-Qanțara (AQ) XXX 2, julio-diciembre 2009, pp. 581-622 ISSN 0211-3589 


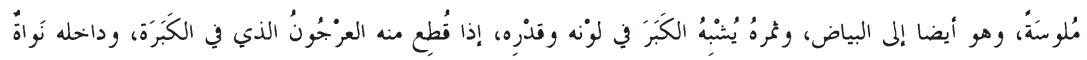

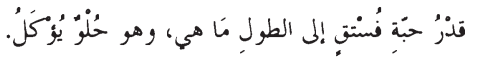

Recibido: 16/06/2009

Aceptado: 24/06/2009

Al-Qanțara (AQ) XXX 2, julio-diciembre 2009, pp. 581-622 ISSN 0211-3589 